ARTICLE

Received 12 Nov 2013 | Accepted 30 May 2014 | Published 8 Jul $2014 \quad$ DOl: 10.1038/ncomms5259

\title{
IL-23 promotes TCR-mediated negative selection of thymocytes through the upregulation of IL-23 receptor and ROR $\gamma \mathrm{t}$
}

Hao Li ${ }^{1,2}$, Hui-Chen Hsu', Qi Wu' ${ }^{1}$, PingAr Yang ${ }^{1}$, Jun Li ${ }^{1}$, Bao Luo ${ }^{1}$, Mohamed Oukka ${ }^{3}$, Claude H. Steele III ${ }^{4}$, Daniel J. Cua ${ }^{5}$, William E. Grizzle ${ }^{6}$ \& John D. Mountz ${ }^{1,7}$

Transient thymic involution is frequently found during inflammation, yet the mode of action of inflammatory cytokines is not well defined. Here we report that interleukin-23 (IL-23) production by the thymic dendritic cells (DCs) promotes apoptosis of the CD4 ${ }^{\text {hi }} \mathrm{CD} 88^{\text {hi }}$ double-positive (DP) thymocytes. A deficiency in IL-23 signalling interferes with negative selection in the male $D^{\mathrm{b}} / \mathrm{H}-\mathrm{Y}$ T-cell receptor (TCR) transgenic mice. IL-23 plus TCR signalling results in significant upregulation of IL-23 receptor (IL-23R) expressed predominantly on $\mathrm{CD} 4{ }^{\text {hi }} \mathrm{CD} 8{ }^{\text {hi }} \mathrm{CD} 3{ }^{+} \alpha \beta T C R+$ DP thymocytes, and leads to ROR $\gamma \mathrm{t}$-dependent apoptosis. These results extend the action of IL-23 beyond its peripheral effects to a unique role in TCRmediated negative selection including elimination of natural T regulatory cells in the thymus.

\footnotetext{
${ }^{1}$ Division of Clinical Immunology \& Rheumatology, Department of Medicine, University of Alabama at Birmingham, Birmingham, Alabama 35294, USA.

${ }^{2}$ Department Microbiology, University of Alabama at Birmingham, Birmingham, Alabama 35294, USA. ${ }^{3}$ Department of Pediatrics, University of Washington, Seattle, Washington 98195, USA. ${ }^{4}$ Division of Pulmonary, Allergy \& Critical Care, Department of Medicine, University of Alabama at Birmingham,

Birmingham, Alabama 35294, USA. ${ }^{5}$ Merck Research Laboratories, Palo Alto, California 94304, USA. ${ }^{6}$ Clinical Pathology \& Anatomic Pathology, University of Alabama at Birmingham, Birmingham, Alabama 35294, USA. ${ }^{7}$ Birmingham VA Medical Center, Birmingham, Alabama 35233, USA. Correspondence and requests for materials should be addressed to H.-C.H. (email: rheu078@uab.edu) or to J.D.M. (email: jdmountz@uab.edu).
} 
T he thymic environment orchestrates the development of the diverse repertoire of functional $\mathrm{T}$ cells that is required for a robust adaptive immune response to foreign antigens (Ags) while minimizing the generation of $\mathrm{T}$ lymphocytes that can attack normal tissues and drive autoimmunity ${ }^{1}$. One key control point in the thymus to maintain self-tolerance involves deletion of those late-stage $\mathrm{CD} 4{ }^{+} \mathrm{CD} 8{ }^{+}$double-positive (DP) thymocytes that express autoreactive $\alpha \beta$ TCRs and can interact with moderate to high affinity with thymic dendritic cells (DCs) presenting self- $\mathrm{Ags}^{2-4}$. Although other antigen-presenting cells in the thymus are involved in negative selection, the high levels of expression of major histocompatibility (MHC) and costimulatory molecules on the DCs make them essential for efficient negative selection ${ }^{5-7}$.

The synchronized transitions of the gene expression profiles of the developing thymocytes are associated with alterations in the activity of critical transcription factors. One of these, the thymusspecific isoform of the retinoic acid receptor-related orphan receptor (ROR $\gamma \mathrm{t}$ ) is normally only expressed at high levels in early-stage DN and DP thymocytes. It promotes the development and survival of the early-stage DP thymocytes, following expression of the $\alpha \beta T C R$, by activating transcription of the gene encoding the anti-apoptotic protein $\mathrm{Bcl}-\mathrm{xL}^{9,10}$, which then inhibits the transcription of $c$-Rel and $I l 2$ (refs 8,11). During the later stages of thymocyte development, downregulation of $\mathrm{ROR} \gamma \mathrm{t}$ is essential for the maturation of DP thymocytes into SP thymocytes because ROR $\gamma \mathrm{t}$ transgene expression in mature $\mathrm{T}$ cells affects their multiple functions including enhanced apoptosis and reduced proliferation ${ }^{8,12,13}$. It has been reported that ectopic overexpression of ROR $\gamma \mathrm{t}$ results in apoptosis instead of survival of DP in transition to SP thymocytes ${ }^{14}$. Thus, regulation of ROR $\gamma \mathrm{t}$ can be one factor deciding the fate of latestage DP thymocytes.

The signalling mechanisms that regulate ROR $\gamma \mathrm{t}$ expression in late-stage DP thymocytes have not been identified. It has been shown that interleukin-23 (IL-23), a highly conserved member of the IL-12 family of regulatory cytokines that is primarily produced by DCs and macrophages ${ }^{15,16}$, signals through ROR $\gamma \mathrm{t}$ in activated CD4 $\mathrm{T}$ cells in the periphery ${ }^{17-19}$. In the present study, we investigated whether IL-23 acts through the regulation of ROR $\gamma$ t to regulate thymocyte selection. We have made an interesting observation that deficiency of the p19

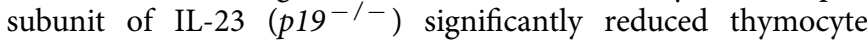
apoptosis following Aspergillus fumigatus infection in B6 mice. It also perturbed thymic negative selection in male Il23 $\mathrm{p}^{1} 9^{-/-}$ $\mathrm{D}^{\mathrm{b}} / \mathrm{H}-\mathrm{Y}$ T-cell receptor (TCR) transgenic (Tg) mice without affecting thymocyte-positive selection in female Il23 $\mathrm{p} 19^{-/-} \mathrm{D}^{\mathrm{b}} /$ H-Y TCR Tg mice. Overexpression of IL-23 leads to enhanced apoptosis and depletion of late-stage DP thymocytes by upregulation of ROR $\gamma \mathrm{t}$ and IL-23 receptor (IL-23R) via a TCR/ CD3-dependent mechanism. The finding of IL-23-dependent negative selection may indicate a novel central regulation mechanism mediated by a cytokine that is proinflammatory in the periphery.

\section{Results}

IL-23 drives thymocyte apoptosis during infection. IL-23 is important in regulating clearance of pathogen ${ }^{20-22}$, but also is associated with inflammation in autoimmune diseases, multiple sclerosis $^{23,24}$, rheumatoid arthritis ${ }^{25}$ and lupus ${ }^{26}$. In an attempt to study the anti-fungal effect of IL-23 in clearance of A. fumigatus, we have made a surprising observation that despite the essential role of IL-23 in maintaining host resistance to this pathogen (Supplementary Fig. 1a), there was a substantial reduction in thymic size and total thymocyte count on day 4 in normal B6 mice (Supplementary Fig. 1b). Terminal deoxynucleotidyl transferase dUTP nick-end labelling (TUNEL) and 7-amino actinomycin D staining indicated that the loss of thymocytes in wild-type (WT) B6 mice was associated with a dramatically increased apoptosis of $\mathrm{CD}^{+} \mathrm{CD} 8{ }^{+}$DP thymocytes (Supplementary Fig. 1c,d). Fluorescence-activated cell sorting (FACS) analysis showed a significant elimination of the $\mathrm{CD} 4{ }^{+} \mathrm{CD}^{+}$DP population (Supplementary Fig. 1e). In contrast, although a deficiency of IL-23 in B6-Il23 $\mathrm{pl}^{-/-}$ mice enhanced A. fumigatus-induced mortality, the massive loss of thymic cellularity and DP thymocytes were largely circumvented (Supplementary Fig. 1a-e). Interestingly, IL-23R, which was detected in a small percent of DP thymocytes of naïve mice, was significantly upregulated on day 3 in DP thymocytes of A. fumigatus-infected WT but not B6-Il23 $p 19^{-/-}$ mice (Supplementary Fig. 1f). During the course of infection, IL-23 levels were dramatically elevated between days 1-2 (Supplementary Fig. 1g). These above findings suggest an interesting concept that IL-23 may potentially affect thymic output.

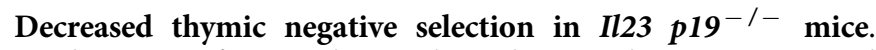
To determine if IL-23 play a role in thymic selection, we crossed Il23 $\mathrm{p}^{19^{-/}}$to $\mathrm{D}^{\mathrm{b}} / \mathrm{H}-\mathrm{Y}$ TCR Tg background and examined thymocyte negative or positive selection in the male versus female mice, respectively ${ }^{27-29}$, to determine if IL-23 directly plays a role in regulating thymocyte development. In the male mice, the cortical area of the thymus of the Il23 $p 19^{-/-} \mathrm{D}^{\mathrm{b}} / \mathrm{H}-\mathrm{Y}$ TCR mice was enlarged compared with the Il23 $\mathrm{p} 9^{+/+} \mathrm{D}^{\mathrm{b}} / \mathrm{H}-\mathrm{Y}$ TCR mice (Fig. 1a). The thymi were not overtly different in the female Il23 p19-/- $\mathrm{D}^{\mathrm{b}} / \mathrm{H}-\mathrm{Y}$ TCR Tg mice compared with the female Il23 p19 ${ }^{+/+} \mathrm{D}^{\mathrm{b}} / \mathrm{H}-\mathrm{Y}$ TCR Tg mice (Fig. 1b).

There were a higher percentage and increased cell counts of both DP and $\mathrm{CD}^{+}$SP thymocytes in the Il23 $\mathrm{pl9}^{-/-}$

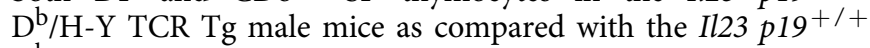
$\mathrm{D}^{\mathrm{b}} / \mathrm{H}-\mathrm{Y}$ TCR Tg male mice, which is consistent with a defect in thymic negative selection (Fig. 1c-e). The lack of significant differences in the sizes of the thymocyte subpopulations in the female Il23 $p 19^{+/+} \mathrm{D}^{\mathrm{b}} / \mathrm{H}-\mathrm{Y}$ TCR Tg mice and female Il23 $p 19^{-/-}$ $\mathrm{D}^{\mathrm{b}} / \mathrm{H}-\mathrm{Y}$ TCR Tg mice further suggests that IL-23 is not involved in thymic positive selection (Fig. $1 \mathrm{f}-\mathrm{h}$ ). The thymic negative selection is a highly specialized process for DP thymocytes that takes place in the thymic medullary areas where tissue-restricted Ags in the periphery are presented. Consistently, the majority of TUNEL $^{+}$cells were detected in the inner cortex and the medullary area near the vicinity of the thymic $\mathrm{S}_{100}{ }^{+}$DCs in $\mathrm{Il} 23$ $p 19^{+/+} \mathrm{D}^{\mathrm{b}} / \mathrm{H}-\mathrm{Y}$ TCR Tg thymus (Fig. 1i). The numbers of the apoptotic cells were dramatically lower in the $I l 23 \mathrm{p}^{-9^{-/}} \mathrm{D}^{\mathrm{b}} / \mathrm{H}-$ Y TCR Tg male mice (Fig. 1i) and the frequency of apoptotic thymocytes was significantly lower, especially in thymic medullary areas of the Il23 $p 19^{-}-\mathrm{D}^{\mathrm{b}} / \mathrm{H}-\mathrm{Y}$ TCR Tg male than in the Il23 $p 19^{+/+} \mathrm{D}^{\mathrm{b}} / \mathrm{H}-\mathrm{Y}$ Tg male mice (Fig. 1j). There was a significantly higher expression of IL-23R on DP thymocytes in Il23 $\mathrm{pl}^{+} \mathrm{9}^{+}+\mathrm{D}^{\mathrm{b}} / \mathrm{H}-\mathrm{Y}$ TCR Tg male mice comparing with Il23 $p 19^{-/-} \mathrm{D}^{\mathrm{b}} / \mathrm{H}-\mathrm{Y}$ TCR Tg male mice (Supplementary Fig. 2a). Interestingly, the IL-23R expression on DN thymocytes from both strains are not detectable even those cells have early expression of Tg TCR (Supplementary Fig. 2a). Together, these results suggested that there is tight temporal and spatial regulation of IL-23-mediated thymic selection.

Decreased thymocyte apoptosis in naïve B6-Il23 $\mathrm{pl9}^{-/-}$mice. To further verify our findings, we determined the tissue related expression of $I l 23$ p19 and Il23r in naïve C57BL/6 mice. The results showed that, compared with spleen, lymph nodes, kidney, 
a

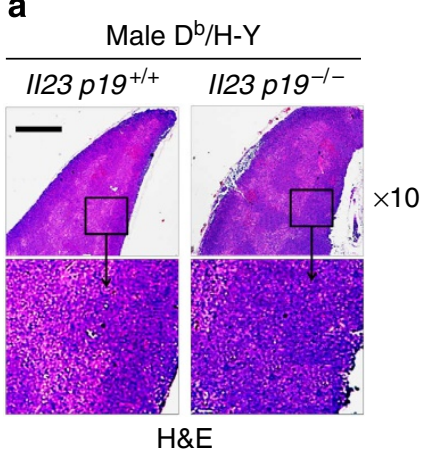

c
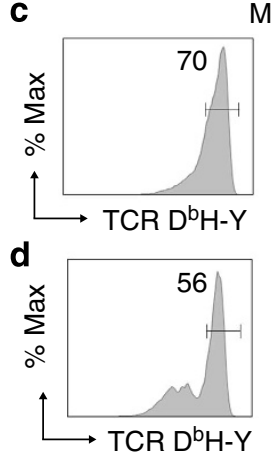

Male
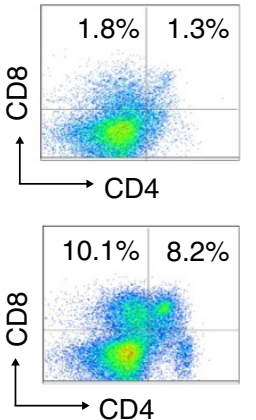

f

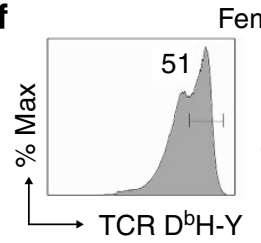

Female

\section{g}

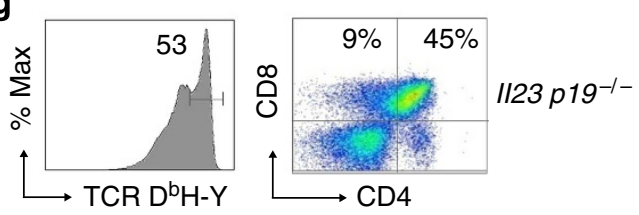

b

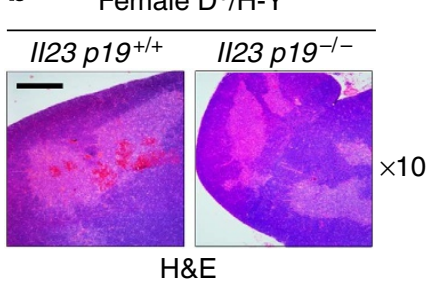

e

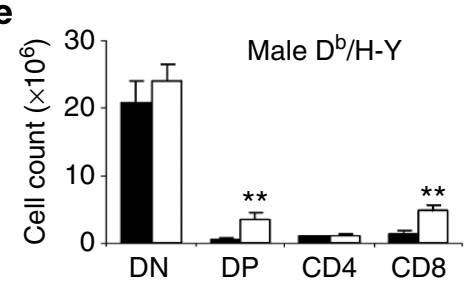

h

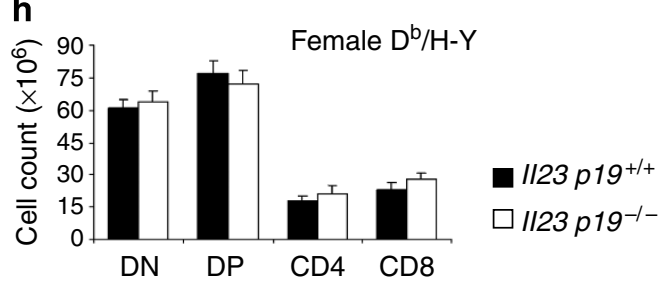

i

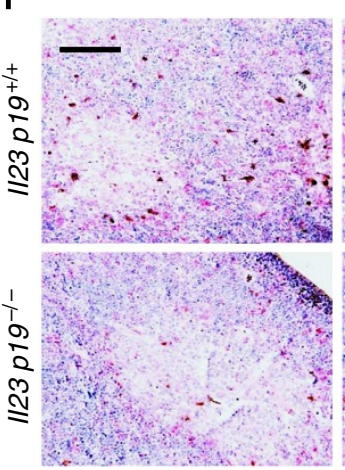

$\times 20$
Male $\mathrm{D}^{\mathrm{b} / \mathrm{H}-\mathrm{Y}}$

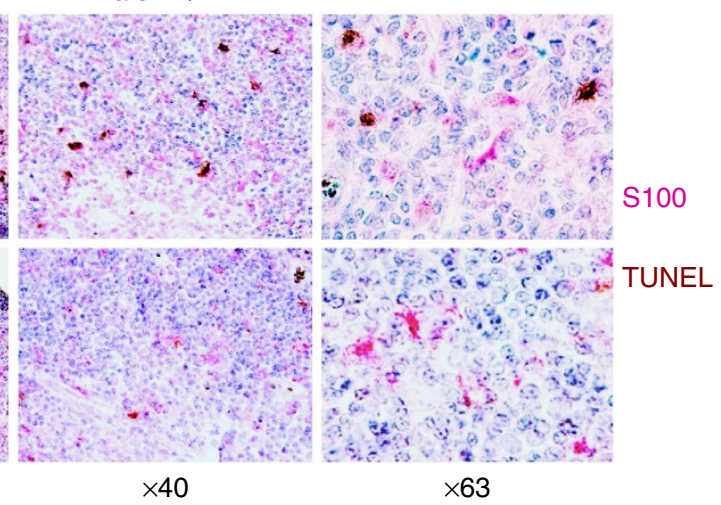

j
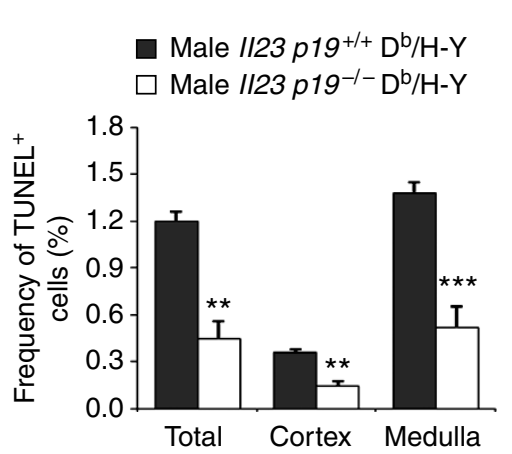

Figure 1 | Decreased thymic negative selection in $\mathbf{1 2 3}$ p19-/- mice. (a) Hematoxylin and eosin (H\&E) staining of thymus from the indicated male mice.

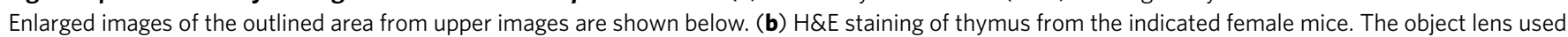
to acquire the images is shown. Scale bars in $\mathbf{a}$ and $\mathbf{b}, 300 \mu \mathrm{m}$. (c-h) Flow cytometry analysis of the frequency of $\mathrm{H}-\mathrm{Y}$ TCR ${ }^{+}$thymocytes and the distribution of CD4/CD8 in H-Y TCR ${ }^{+}$thymocytes in (c) male $/ 123$ p19+/ $+\mathrm{Tg}$, (d) male $/ 123$ p19-/ $-\mathrm{Tg}$, (f) female $/ 123$ p19+/ $+\mathrm{Tg}$ and (g) female $/ 123$ p19-/- Tg mice. In each group, all samples were gated first on Thy1.2 ${ }^{+}$cells. Numbers shown within each quadrant indicate the percent cells in the quadrant. Cell counts of the indicated populations of thymocytes (e,h). All populations were gated within the TCR $\mathrm{D}^{\mathrm{b}} / \mathrm{H}^{-} \mathrm{Y}^{+}$thymocytes. $\mathrm{All}$ results shown were calculated based on the percentage of each subpopulation of thymocytes multiplied by the total thymocyte count multiplied by $10-6$. (i) Immunohistochemistry staining of thymic DCs (S100 ${ }^{+}$, magenta) and apoptotic cells (TUNEL ${ }^{+}$, dark brown). The object lens used to acquire each panel of image is shown at the bottom. Scale bar, $100 \mu \mathrm{m}$. (j) The percentage of TUNEL ${ }^{+}$cells at the indicated thymic region was quantified in five

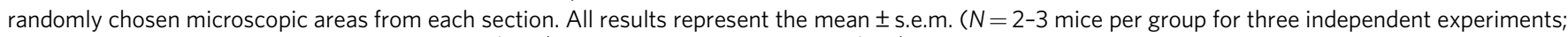
${ }^{\star \star} P<0.01$ and ${ }^{\star \star \star} P<0.005$ between $p 19 \| 23^{+/+} \mathrm{D}^{\mathrm{b}} / \mathrm{H}-\mathrm{Y} \mathrm{Tg}$ male and $\mathrm{p} 19 \| 123^{-/}-\mathrm{D}^{\mathrm{b}} / \mathrm{H}-\mathrm{Y} \mathrm{Tg}$ male mice).

liver and colon, thymus expresses higher levels of both Il23 and Il23r (Supplementary Fig. 2b). Within the different populations of cells sorted from the thymus of naive B6 mice using the protocol shown in Supplementary Fig. 3 (refs 30,31), thymic DCs expressed dramatically higher levels of Il23, compared with cortical epithelial cells and medullary thymic epithelial cells (Fig. 2a). Furthermore, Il23r, but not Il23, mRNA was detectable in Thy $1.2^{+}$thymocytes (Fig. 2b). Within subpopulations of thymocytes, the levels of $I l 23 r$ were the highest in $\mathrm{CD} 4{ }^{\text {hi }} \mathrm{CD} 8{ }^{\text {hi }}$ DP thymocytes and were almost undetectable in DN and CD8 SP cells (Fig. 2b). Il23r was also detected in thymic epithelial cells and DCs (Fig. 2b).

The specificity of a polyclonal anti-IL-23R antibody was confirmed by analysis on in vitro polarized Th17 and Th1 cells generated from heterozygous IL-23R-green fluorescent protein
(GFP) knock-in mouse spleen ${ }^{32,33}$ (Supplementary Fig. 4). Using this anti-IL-23R antibody, we have identified that IL-23R was expressed by a small percent of thymocytes and the majority of these cells were within the $\mathrm{CD} 4{ }^{+} \mathrm{CD} 8{ }^{+} \mathrm{DP}$ thymocyte population (Fig. 2c). The IL-23R ${ }^{+}$population was almost undetectable in IL-23R-deficient mice (Fig. 2c). Interestingly, the percent of this small population of IL- $23 \mathrm{R}^{+} \mathrm{CD} 4{ }^{\text {hi }} \mathrm{CD} 8{ }^{\text {hi }} \mathrm{DP}$ thymocytes gradually decreases with increasing age, suggesting the close association with the rate of thymopoiesis (Fig. $2 \mathrm{~d}$ and Supplementary Fig. 5).

We next determined if a deficiency of $I l 23$ was associated with decreased apoptosis. In situ TUNEL staining revealed that the numbers of thymocytes undergoing apoptosis were reduced in Il23 $\mathrm{p}^{-/ 9^{-/}}$mice compared with WT B6 mice (Fig. 2e), and the reduction was apparent especially in the inner cortex and 

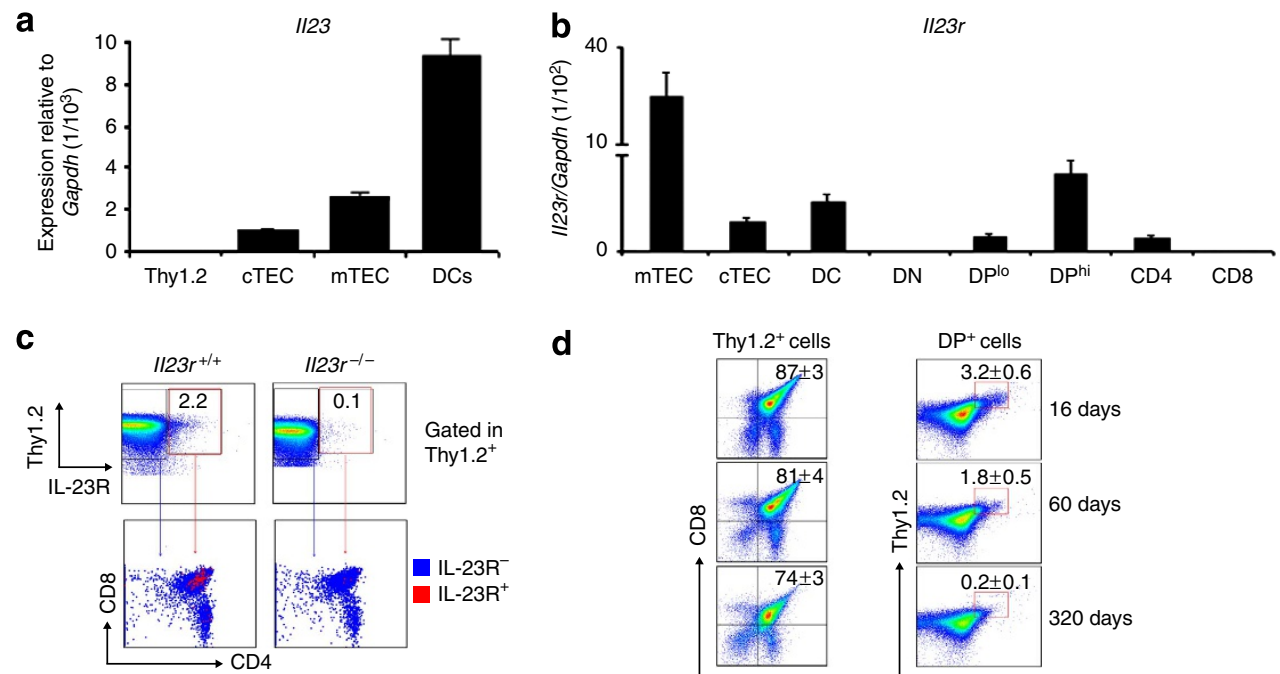

d
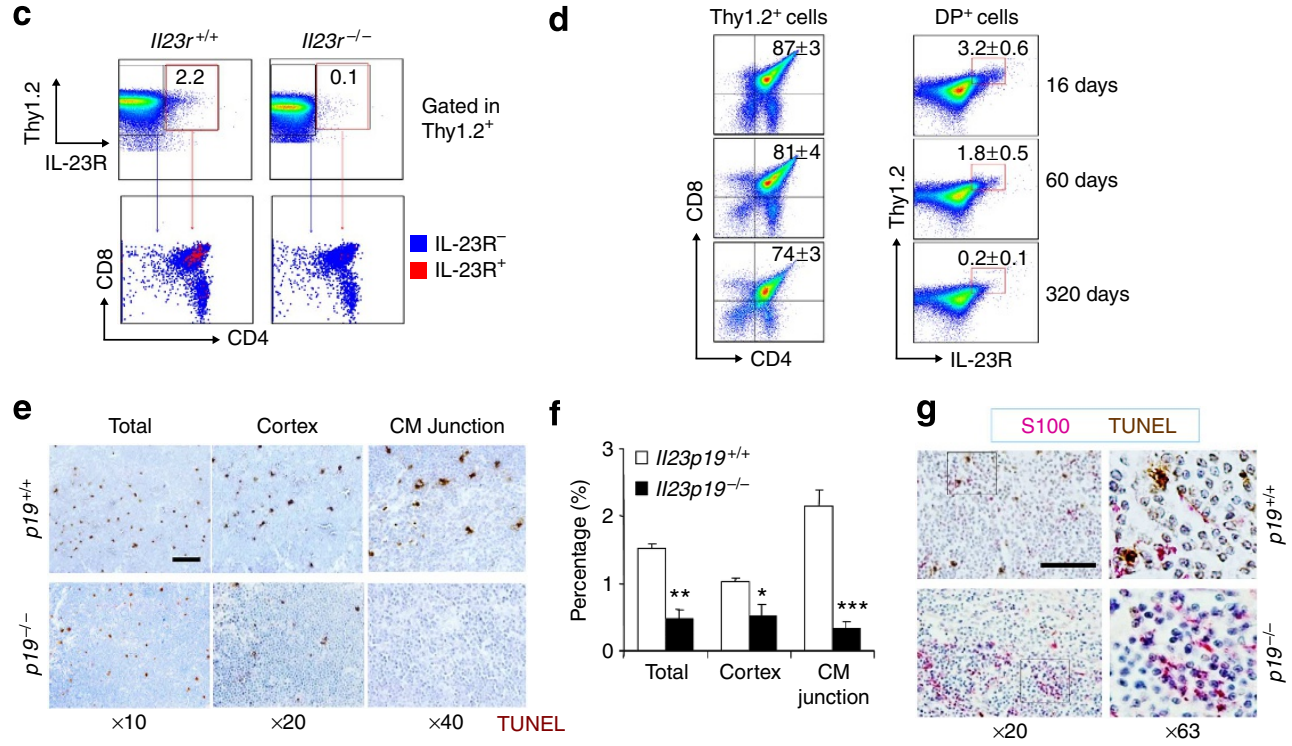

Figure 2 | Decreased apoptosis in thymus of $\| \mathbf{2 3} \mathbf{p} \mathbf{1 9}^{-/-}$mice. $(\mathbf{a}, \mathbf{b})$ Quantitative real-time PCR analysis of $I 123(\mathbf{a})$ and $I / 23 r(\mathbf{b})$ in the indicated thymic subpopulations of 2-month-old B6 mice. Data are representative of two independent experiments (mean \pm s.e.m., $N=2-3$ mice per experiment). (c) Flow cytometry analysis of IL-23R ${ }^{+}$thymocyte subpopulation distribution. Thymocytes were gated on Thy1.2 ${ }^{+} \mathrm{IL}-23 \mathrm{R}^{+}$or Thy $1.2^{+} \mathrm{IL}-23 \mathrm{R}^{-}$separately, each population was analysed for expression of CD4 and CD8. (d) Flow cytometry analysis of IL-23R expression in CD4 ${ }^{+} \mathrm{CD} 8{ }^{+} \mathrm{DP}$ thymocyte from mice of the indicated ages. Thymocytes were gated on Thy $1.2^{+}$population and were analysed for expression of CD4 and CD8 (left). Cells within the DP Thy $1.2^{+}$subpopulation were analysed for expression of IL-23R (right). (e) In situ TUNEL staining on thymus sections of 1123 p19+/ + or 1123 p19-/C57BL/6J mouse. The magnification of the objective lens used for each panel is shown in the bottom. (f) BioQuant image analysis on the percentage of $\mathrm{TUNEL}^{+}$cells. Five microscopic areas were randomly chosen for the quantitation of each section. Data in c-f are representative of three independent experiments (mean \pm s.e.m., $N=2-3$ mice per group; ${ }^{\star} P<0.05$, ${ }^{\star \star} P<0.01,{ }^{\star \star \star} P<0.005$ between $I 123 p 19^{+/ t}$ and $1123 p 19^{-/-}$mice). (g) In situ staining of thymic DCs and apoptotic thymocytes using S100 (magenta) and TUNEL staining (brown), respectively. The magnification of the objective lens used for each panel is shown below the images. Scale bar, $100 \mu \mathrm{m}$, applies to all panels.

cortical-medullary junction (Fig. 2f). The location of TUNEL ${ }^{+}$ thymocytes was determined along with co-staining for $\mathrm{S} 100^{+}$ thymic DCs. In WT B6 mice, TUNEL $^{+}$thymocytes were predominately found in close proximity to the $\mathrm{S} 00^{+}$thymic DCs. In contrast, in Il23 $p 19^{-/-}$B6 mice, there were fewer TUNEL $^{+}$apoptotic thymocytes (Fig. 2g). These results are consistent with findings derived from $A$. fumigatus-infected mice or $\mathrm{D}^{\mathrm{b}} / \mathrm{H}-\mathrm{Y}$ TCR Tg male mice to suggest that the major function of IL-23R signalling in the thymus is to induce thymocyte apoptosis.

Delayed apoptosis induced by IL-23 in the thymus. To enable us to follow the kinetics of IL-23-mediated thymocyte apoptosis, exogenous IL-23 was induced by administration of an adenovirus that carries the mouse $I l 23$ gene (AdIL-23) to naïve B6 mice ${ }^{34,35}$. An adenovirus carrying the $L a c Z$ gene (AdLacZ) was used as a control. The serum levels of IL-23 in the AdIL-23-injected mice were increased over baseline by day 3 , reached the maximal value at day 5 , were maintained until day 9 and returned to baseline by day 10 (Supplementary Fig. 6a). The size of the thymus and its cellularity began to diminish in the AdIL-23-injected mice on day 7 (2 days after the peak level of IL-23 in the sera) (Fig. 3a and Supplementary Fig. $6 \mathrm{~b}$ ). Consistent with this, the most significant depletion of the DP thymocytes occurred on day 9 (Supplementary Fig. 6b). Flow cytometry analysis revealed that the earliest depletion could be observed in the CD $4{ }^{\text {hi }} \mathrm{CD} 8{ }^{\text {hi }}$ population 5 days after administration of the AdIL-23 whereas the $\mathrm{CD} 4{ }^{\mathrm{lo}} \mathrm{CD} 8{ }^{\text {lo }}$ population became involved somewhat later (by day 7), with the greatest decrease seen at day 9 (Fig. 3b and Supplementary Table 1). Histological staining confirmed a delayed loss of the thymic cortex after AdIL-23 administration (Fig. $3 c$ and Supplementary Table 2). This loss correlated with a dramatically higher level of apoptosis and lower proliferation of thymocytes (Fig. 3d,e, and Supplementary Table 2). z-VAD, a pan-caspase inhibitor, in vivo treatment significantly blocked the IL-23-mediated thymic cellularity loss, which suggests that IL-23 primarily acts through induction of apoptosis to diminish thymus size and thymocyte count in mice (Supplementary Fig. 7). Interestingly, the delayed peak of apoptosis after AdIL-23 does not correlate with the early phase of cytokine induction, and is not observed in control AdLacZ-administered mice.

IL-23R is required for IL-23-induced thymocyte apoptosis. Based on the finding in A. fumigatus-infected mice that IL-23R upregulation was associated with the massive thymocyte apoptosis, we determined if the delayed onset of exogenous 
a

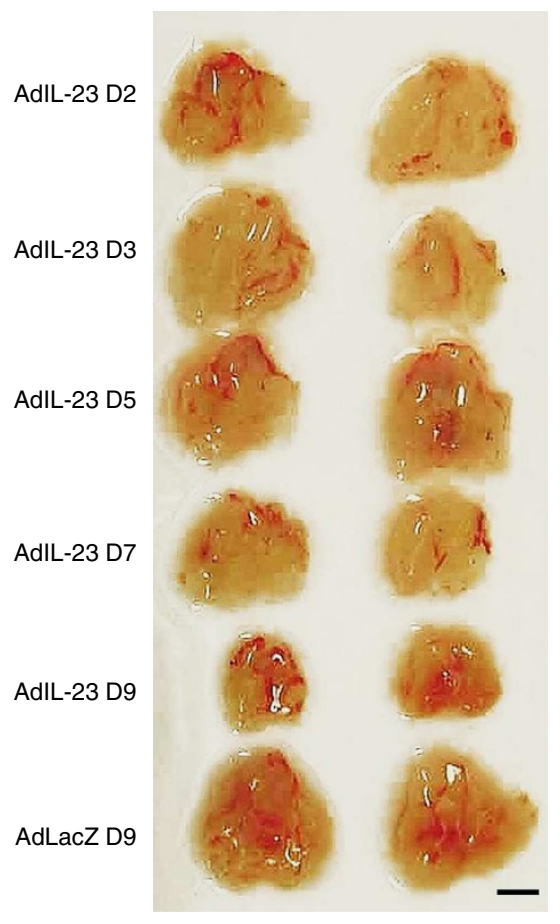

b

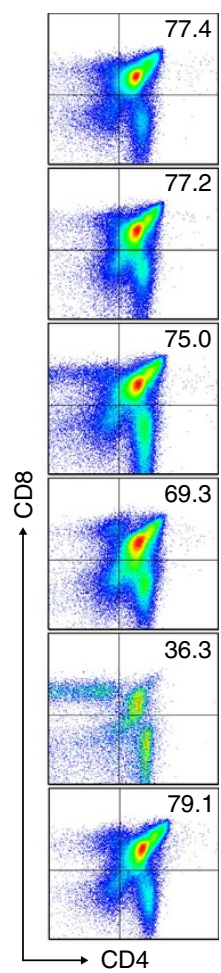

c

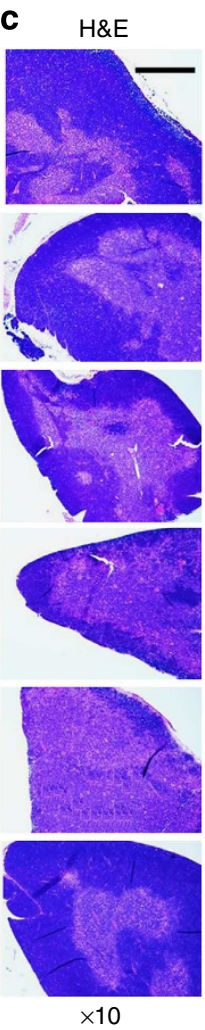

d TUNEL
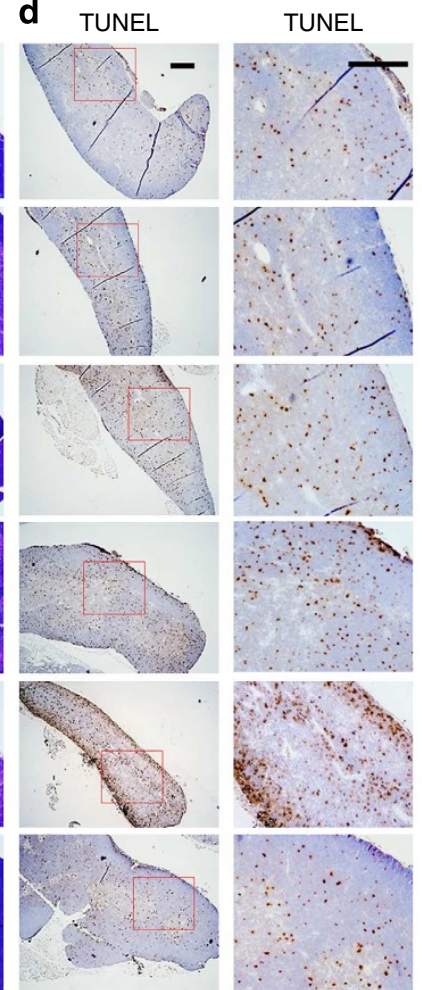

$\times 4$ e $\quad \mathrm{Ki67}$

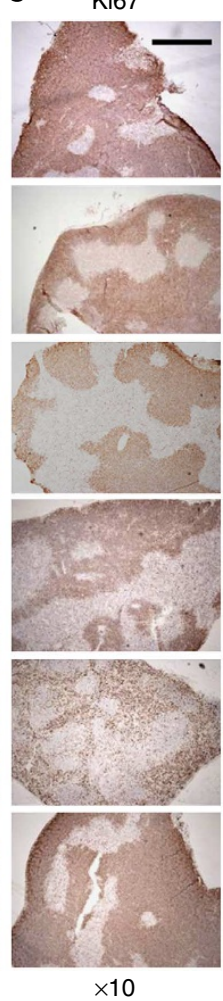

Figure 3 | Delayed apoptosis induced by IL-23 in the thymus. C57BL/6 mice were injected with either AdIL-23 or AdLacZ. At the indicated day (D), mice were killed. (a) Gross anatomical images of representative thymi from each group of mice. Scale bars, $3.0 \mathrm{~mm}$. (b) Flow cytometry analysis of CD4 and CD8 expression on Thy $1.2^{+}$cells and the percent of $\mathrm{CD} 4{ }^{+} \mathrm{CD} 8{ }^{+}$cells is shown. (c) In situ hematoxylin and eosin (H\&E) staining of a representative thymus section. (d) In situ TUNEL staining (dark brown) of a representative thymus section. (e) In situ Ki67 staining (dark brown) of a representative thymus section. The magnification of objective lens used is shown below the images. $N=4-5$ mice per group for three independent experiments. Scale bars c-e, $300 \mu \mathrm{m}$.

AdIL-23-induced thymocyte apoptosis is related to the requirement of IL-23R upregulation. AdIL-23 or AdLacZ was administered to mice that lack the IL-23R (homozygous IL-23RGFP knock-in mice $)^{36}$. Neither the reduction in thymus size nor the depletion of DP thymocytes that was observed in AdIL-23-treated WT $I l 23 r^{+/+}$mice was apparent in the AdIL23-treated Il23r $r^{-/}$mice (Fig. 4a,b; Supplementary Table 3).

To confirm that IL-23R expression on thymocytes, but not other thymic cells including TEC or DCs that also expressed IL-23R, was essential for IL-23-induced apoptosis, bone marrow $(\mathrm{BM})$ reconstitution was carried out in three conditions $(\mathrm{WT} \rightarrow$ $\mathrm{WT}, \mathrm{WT} \rightarrow I l 23 r^{-/-}$and $I l 23 r^{-/-} \rightarrow \mathrm{WT}$ ). In this experimental condition, DCs and macrophages are more susceptible to radiation-induced apoptosis compared with the epithelial cells $\left(\mathrm{CD} 45^{-}\right)^{37,38}$ and thymocytes do not repopulate normally without $\mathrm{TECs}^{39}$. We have identified that in all three groups of chimeric mice, there was nearly complete reconstitution of thymocytes, and almost all were derived from transferred donor BM at Day 40 (Supplementary Fig. 8a,b). The thymic CD11b ${ }^{+}$ or $\mathrm{CD}_{11 \mathrm{c}^{+}}$cells, however, remained as recipient origin (Supplementary Fig. 8c), suggesting that recipient DCs and TECs remained unaffected under the present experimental condition.

AdIL-23 or control AdLacZ was then administered to these three groups of mice. A specific requirement for IL-23R expression on thymocytes to drive apoptosis induced by AdIL23 is indicated by the dramatic decrease in the sizes of the thymi in both WT $\rightarrow$ WT and in WT $\rightarrow I l 23 r^{-/}$mice compared with Il23r ${ }^{-/-} \rightarrow$ WT on day 9 after AdIL-23 administration (Fig. 4c and Supplementary Fig. 8d,e). A significant loss of the thymic cortex and a higher level of apoptosis were shown in the thymi of AdIL-23-administered recipients from both $\mathrm{WT} \rightarrow \mathrm{WT}$ and $\mathrm{WT} \rightarrow I l 23 r^{-/}-$groups compared with $I l 23 r^{-/} \rightarrow$ WT group by histology staining (Fig. $4 \mathrm{~d}, \mathrm{e}$ ). Depletion of the DP thymocytes was also seen in the thymi of AdIL-23-administered WT $\rightarrow$ WT and $\mathrm{WT} \rightarrow I l 23 r^{-/}$groups but was less apparent in those from the $I l 23 r^{-/} \rightarrow$ WT group (Fig. 4f). As only thymocytes derived from $I l 23 r^{+/+}$donor cells exhibited high sensitivity to AdIL-23mediated thymocyte depletion, these results suggest that IL-23R expressed on thymocytes rather than non-thymocytes plays a key role for IL-23-induced thymocyte apoptosis. Consistent with these results, we have identified that AdIL-23 depleted $I l 23 r+1+$ thymocytes but spared $I l 23 r^{-/-}$thymocytes in recipient mice that have been reconstituted with a 50:50 ratio of mixed BM from congenically marked CD45.1 Il23r ${ }^{+/+}+$CD45.2 Il23r ${ }^{-/-}$mice (Supplementary Fig. 9), suggesting the high death rate of IL-23R ${ }^{+}$thymoyctes when encountering IL-23.

IL-23 upregulates IL-23R to amplify IL-23-induced apoptosis. In peripheral T cells, the expression of IL-23R is induced by their activation and further enhanced by IL-23 (refs 17,18). Our data showed that only a minor population of DP thymocytes expressed IL-23R under naïve conditions (Fig. 2c,d and Supplementary Fig. 1f). To determine if AdIL-23 administration could upregulate IL-23R expression prior to the induction of apoptosis, we examined IL-23R expression within the thymus in vivo at different time points after administration of either AdIL-23 or 
a

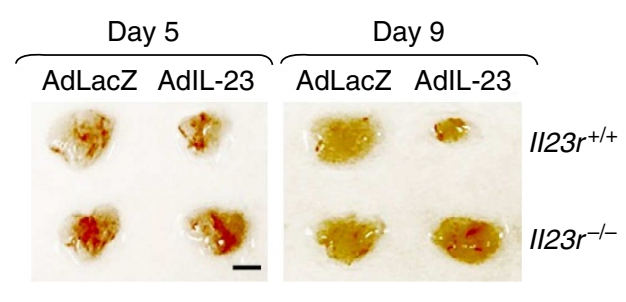

b

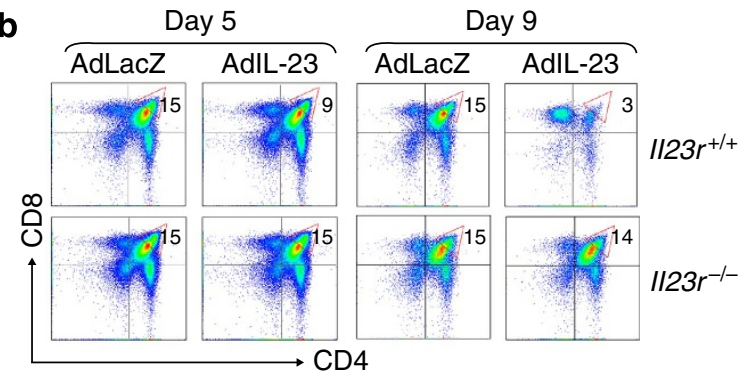

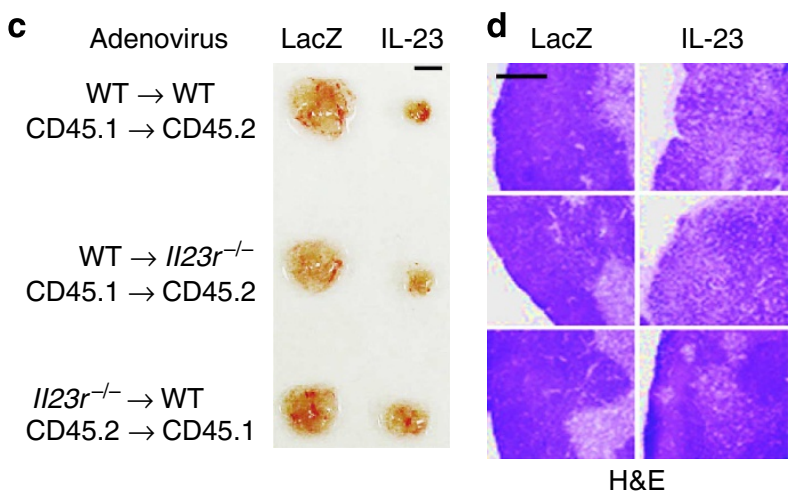
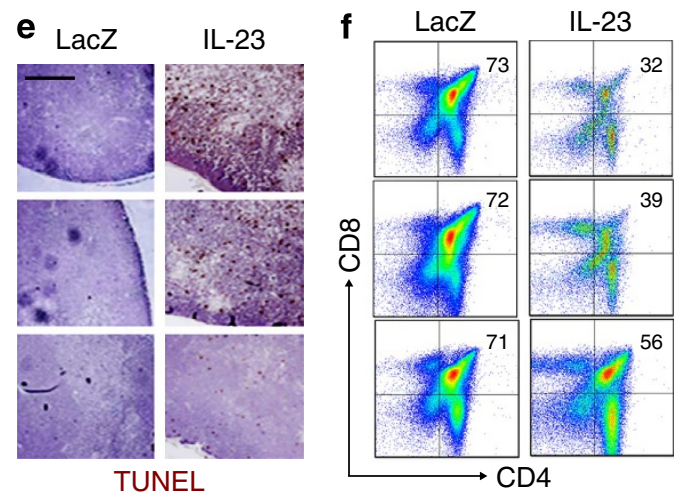

Figure 4 | Induction of IL-23R for IL-23-induced thymocyte apoptosis. (a,b) $1 / 23 r^{+/}+$and $I / 23 r-/-$ mice were administered with either AdIL-23 or AdLacZ. At the indicated time, mice were killed. (a) Gross anatomical images of representative thymi from each group of mice. (b) Flow cytometry analysis of CD4 and CD8 expression on Thy $1.2^{+}$cells and the percent of $\mathrm{CD} 4{ }^{+} \mathrm{CD} 8{ }^{+}$cells are shown. (c-f) BM reconstitution was carried out in the indicated three groups of donor/recipient chimeric mice. Recipient mice were administered with either AdIL-23 or AdLacZ 40 days later. Mice were killed after 9 days. (c) Gross anatomical images of representative thymi. (d) In situ hematoxylin and eosin (H\&E) staining of a representative thymus section. (e) In situ TUNEL staining (dark brown) of a representative thymus section. (f) Flow cytometry analysis of CD4 and CD8 expression on Thy1.2 ${ }^{+}$cells and the percent of $\mathrm{CD}^{+}{ }^{+} \mathrm{CD} 8{ }^{+}$cells are shown. $N=3$ mice per group for two independent experiments. Scale bars in a,c, $3.0 \mathrm{~mm}$; scale bars in d,e, $300 \mu \mathrm{m}$.

AdLacZ. The majority of IL-23R ${ }^{+}$thymocytes were confined to the $\mathrm{CD} 4{ }^{\text {hi }} \mathrm{CD} 8{ }^{\text {hi }} \mathrm{DP}$ subset and the frequency of these IL-23R ${ }^{+}$ $\mathrm{CD} 4{ }^{\text {hi }} \mathrm{CD} 8{ }^{\text {hi }}$ DP thymocytes was significantly higher in the AdIL-23-treated mice than in the AdLacZ-treated mice, especially on day 5 (Fig. 5a). Immunofluorescence confocal microscopy analysis showed a dramatic increase of IL-23R ${ }^{+}$thymocytes in the cortical medulla junction areas of thymus 5 days after AdIL-23 administration (Fig. 5b). Four days later, thymocytes that express IL-23R progressed to apoptosis as indicated by an increased population of IL-23R ${ }^{+}$TUNEL ${ }^{+}$thymocytes (Fig. 5b). We further utilized the heterozygous IL-23R-GFP KI mouse to determine expression of IL- 23R in vivo by GFP fluorescence. Immunofluorescence confocal microscopy analysis indicated that the GFP ${ }^{+}$cells colocalized with Thy $1.2^{+}$cells in the thymus of the AdIL-23-treated IL-23R-GFP KI mice 5 days after treatment (Fig. $5 c, d$, right panels). Few $\mathrm{GFP}^{+}$cells can be detected in the thymi of AdLacZ-treated IL-23R-GFP KI mice (Fig. 5c,d, left panels). These results suggest that AdIL-23 upregulates IL-23R expression and further results in IL-23-mediated apoptosis, which leads to the final loss of IL-23R ${ }^{+}$subpopulation of thymocytes.

IL-23R-ROR $\gamma$ t-mediated CD4 ${ }^{\text {hi }}$ CD8 ${ }^{\text {hi }}$ DP thymocyte apoptosis. The roles of ROR $\gamma t$ in thymocyte maturation and differentiation have been an interesting question as both ROR $\gamma \mathrm{t}$-deficient mice and ROR $\gamma \mathrm{t}$ transgene ( $\mathrm{Tg}$ ) mice have dramatically decreased cellularity in the thymus, ${ }^{8,10}$. If IL-23-IL-23R primarily acts on late-stage DP thymocyte apoptosis, this suggests that IL-23 may preferentially regulate the expression of ROR $\gamma t$ in late versus early DP thymocytes. Comparison of the transcription levels of Rorc and $I l 23 r$ in FACS-sorted $\mathrm{CD} 4{ }^{\text {hi }} \mathrm{CD} 8{ }^{\text {hi }}$ DP thymocytes and
$\mathrm{CD} 4{ }^{\text {lo }} \mathrm{CD} 8{ }^{\text {lo }}$ DP thymocytes from either AdLacZ-treated or AdIL-23-treated mice 5 days after treatment revealed that the levels of Rorc and Il23r were similar in FACS-purified $\mathrm{CD} 4{ }^{\mathrm{lo}} \mathrm{CD} 8{ }^{\text {lo }} \mathrm{DP}$ thymocytes from mice administered with AdIL-23 or AdLacZ (Fig. 6a). In contrast, the FACS-purified $\mathrm{CD} 4{ }^{\text {hi }} \mathrm{CD} 8{ }^{\text {hi }}$ DP thymocytes from mice administered with AdIL-23 exhibited significantly higher levels of Rorc and Il23r than FACS-purified $\mathrm{CD} 4{ }^{\mathrm{hi}} \mathrm{CD} 8 \mathrm{hi}$ DP thymocytes from AdLacZ-treated mice (Fig. 6a), suggesting that late-stage DP thymocytes are sensitive to AdIL-23-induced upregulation of both $I l 23 r$ and Rorc.

Complete absence of ROR $\gamma$ t leads to survival defects of early DP thymocytes ${ }^{10}$ and will not be informative to address the selective effects of ROR $\gamma \mathrm{t}$ in late-stage DP thymocytes. To circumvent this, we utilized heterozygous $\operatorname{Rorc}^{+/}$mice to determine if lower expression of Rorc could partially rescue $\mathrm{CD} 4{ }^{\text {hi }} \mathrm{CD} 8^{\text {hi }}$ thymocytes from AdIL-23-mediated apoptosis (Fig. 6b). On day 9 after AdIL-23 or AdLacZ administration, the frequency of DP thymocytes was similar in the control AdLacZ-treated Rorc ${ }^{+1-}$ and Rorc ${ }^{+1+}$ mice. The frequency of DP thymocytes in the AdIL-23-treated mice Rorc ${ }^{+/-}$mice was comparable to that in the AdLacZ-treated $\operatorname{Rorc}^{+/}-$mice but was substantially higher than in the AdIL-23-treated Rorc ${ }^{+/+}$mice (Fig. 6b). The cell count confirmed that DP, especially those $\mathrm{CD} 4{ }^{\text {hi }} \mathrm{CD} 8^{\text {hi }}$ thymocytes from Rorc $^{+/-}$mice are much less sensitive to IL-23-induced apoptosis compared with Rorc $+/+$ mice (Supplementary Table 3). Moreover, at day 5 post-AdIL-23 treatment, before the dramatic deletion of DP thymocytes, the induction of $\mathrm{Il} 23 \mathrm{r}$ in the $\mathrm{CD} 4{ }^{\mathrm{hi}} \mathrm{CD} 8{ }^{\text {hi }} \mathrm{DP}$ thymocytes from Rorc $^{+/}$mice was substantially lower than that in Rorc $+1+$ mice (Fig. 6c). These results suggest that IL-23-mediated 


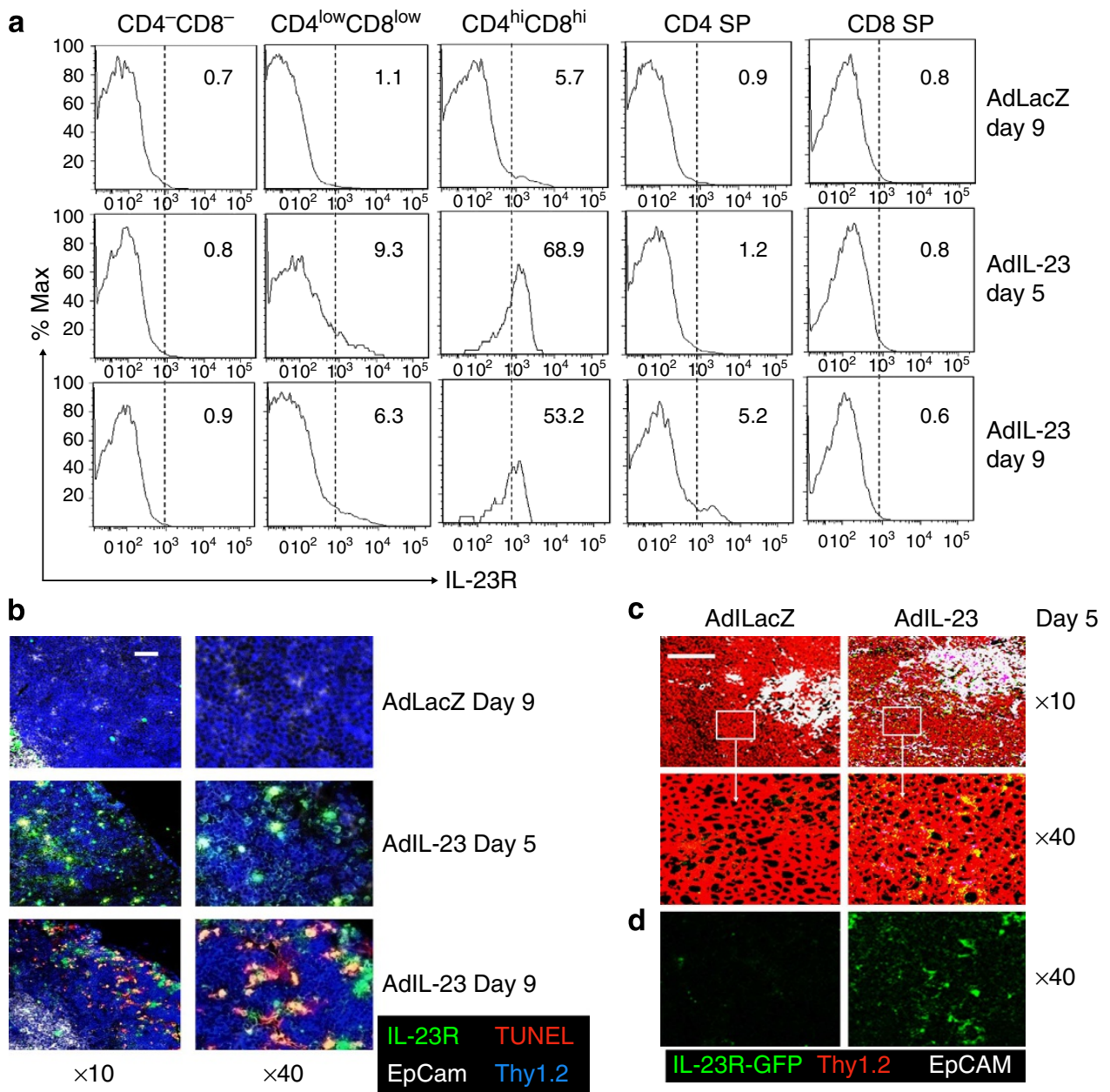

Figure 5 | IL-23 upregulates IL-23R to further promote IL-23-induced apoptosis. (a) Flow cytometry analysis of IL-23R on the indicated thymocyte populations from WT B6 mice at the indicated times after Ad virus administration. The percent of IL-23R ${ }^{+}$cells is shown. (b) Immunofluorescent assessment of IL-23R expression by anti-IL-23R (green) and apoptosis (TUNEL, red) of thymic sections from the indicated mice. Sections were co-stained with A647 anti-CD90.2 (blue) and A555 anti-EpCAM (white). Magnification is shown below the images. (c) Immunofluorescent assessment of IL-23RGFP expression (green) on thymus sections obtained from heterozygous $1 / 23 r^{+/}-$-GFP KI mice 5 days after either AdLacZ or AdIL-23 administration. Sections were co-stained with anti-CD90.2 (red) and anti-EpCAM (white). Magnification is indicated to the right of the images. (d) A single green channel higher power view of the outlined area from $\mathbf{c}$. $N=4-5$ mice per group for three independent experiments. Scale bar, $50 \mu \mathrm{m}$, applies to all panels.

induction of ROR $\gamma \mathrm{t}$ in late-stage $\mathrm{CD} 4{ }^{\text {hi }} \mathrm{CD}{ }^{\text {hi }} \mathrm{DP}$ thymocytes is associated with deletion, but not survival of thymocytes.

Target genes of Rorc in the thymus include $c$-Rel and $B c l-x l$ (refs 8-10,14,40). Analysis of the $\mathrm{CD} 4{ }^{\text {hi }} \mathrm{CD} 88^{\text {hi }}$ DP subset indicated that AdIL-23 treatment was associated with a significant reduction in the levels of $c-$ Rel but did not alter the expression of $B c l-x l$ in this subset in WT mice (Fig. 6d). The levels of both $c$-Rel and $B c l-x l$ in the $\mathrm{CD} 4^{\mathrm{lo}} \mathrm{CD} 8^{\text {lo }}$ thymocytes were unaffected by AdIL-23 treatment. In contrast, partial deficiency of ROR $\gamma \mathrm{t}$ prevented AdIL-23-induced suppression of $c$-Rel in CD $4{ }^{\mathrm{hi}} \mathrm{CD} 88^{\mathrm{hi}}$ but exhibited no effects of its expression in $\mathrm{CD} 4^{\text {lo }} \mathrm{CD} 88^{\text {lo }}$ thymocytes (Fig. 6d). Collectively, these results indicate that IL-23 acts through the IL-23R to upregulate ROR $\gamma \mathrm{t}$ in the latestage DP thymocytes. Downregulation of the levels of $c$-Rel is associated with IL-23-induced thymocyte apoptosis in $\mathrm{CD} 4^{\text {hi }} \mathrm{CD} 8^{\text {hi }}$ late-stage DP but not $\mathrm{CD} 4^{\text {lo }} \mathrm{CD} 8^{\text {lo }}$ early-stage DP thymocytes.

Antigen activation initiates the expression of IL-23R. Negative selection of thymocytes requires a strong TCR-self $\mathrm{Ag}$ interaction $^{29}$. Consistent with the observation that IL-23-mediated thymocytes apoptosis was associated with negative selection, we observed that IL-23R ${ }^{+}$DP cells expressed higher levels of CD3 and $\alpha \beta T C R$ as indicated by gating on the IL-23R ${ }^{+}$population compared with the IL-23R ${ }^{-}$population (Fig. 7a). To determine if loss of TCR stimulation could prevent the upregulation of IL-23R on thymocytes, we administered AdIL- 23 to female $\mathrm{D}^{\mathrm{b}} / \mathrm{H}-\mathrm{Y}$ TCR $\mathrm{Tg}$ mice in which the restricted TCRs were not responsive to all potential endogenous or exogenous Ags during the treatment. Reduction of both the size and cellularity of the thymi were not apparent in female $\mathrm{D}^{\mathrm{b}} / \mathrm{H}-\mathrm{Y}$ TCR Tg mice but could be observed in WT female B6 mice 9 days after AdIL-23 treatment (Fig. 7b). Histological staining confirmed a significant induction of apoptosis in the thymic cortex of AdIL-23-treated female B6 mice but not $\mathrm{D}^{\mathrm{b}} / \mathrm{H}-\mathrm{Y}$ TCR Tg mice (Fig. $7 \mathrm{c}, \mathrm{d}$ ). There was no increase of IL-23R $\mathrm{R}^{+}$DP thymocytes in the thymi of AdIL-23treated female $\mathrm{D}^{\mathrm{b}} / \mathrm{H}-\mathrm{Y}$ TCR Tg mice compared with thymocytes from the B6 counterparts 9 days after AdIL-23 administration at which time, the $\mathrm{CD} 4{ }^{\mathrm{hi}} \mathrm{CD} 8^{\text {hi }}$ population from the thymi of AdIL-23-treated female $\mathrm{D}^{\mathrm{b}} / \mathrm{H}-\mathrm{Y}$ TCR Tg mice was almost not affected by IL-23-mediated apoptosis (Fig. 7e).

To further verify that TCR stimulation is necessary for IL-23-induced thymocyte apoptosis machinery, we co-cultured thymocytes from female $\mathrm{D}^{\mathrm{b}} / \mathrm{H}-\mathrm{Y}$ TCR Tg mice with irradiated 
a

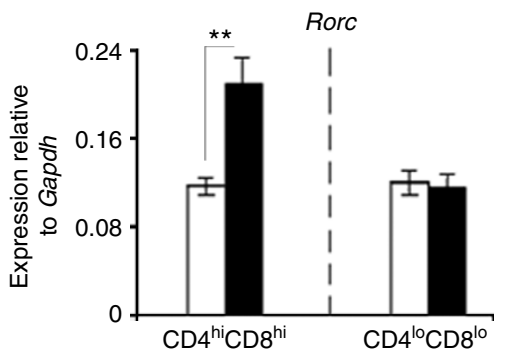

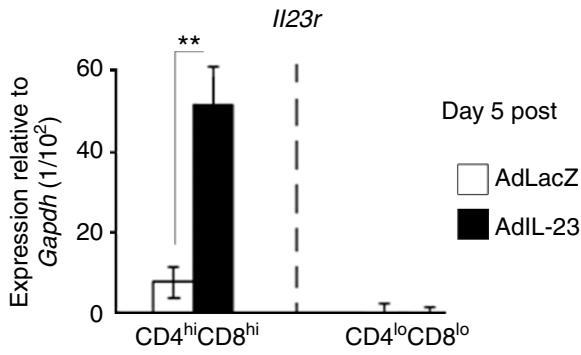

c

(1)

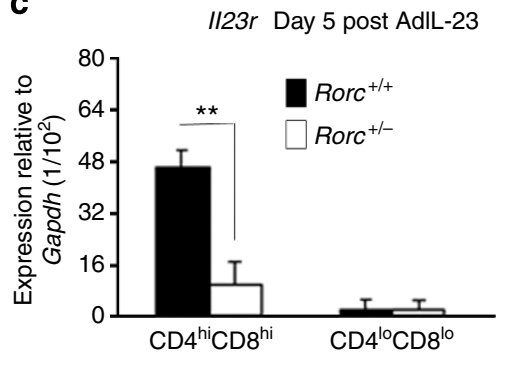

b

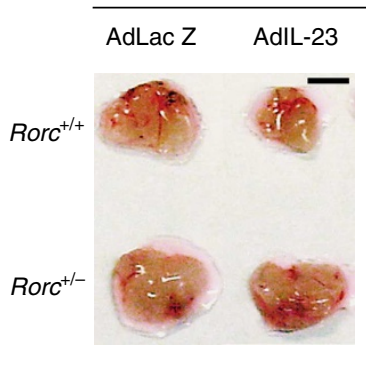

Day 9

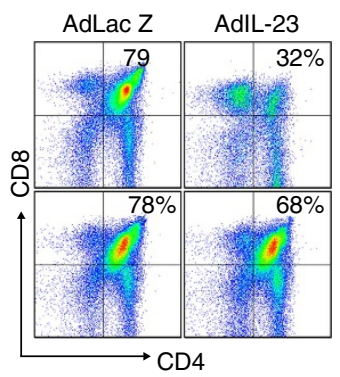

d
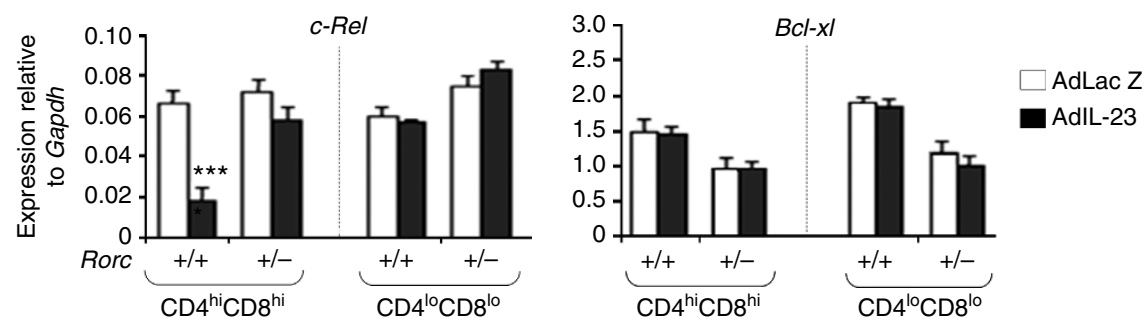

Figure 6 | CD4 ${ }^{\text {hi CD8 }}{ }^{\text {hi }}$ DP thymocytes are targets of IL-23R-ROR $\gamma \mathbf{t}-$ mediated apoptosis. AdLacZ or AdIL-23 was administered to WT (Rorc $+/+$ ) or Rorc $+/$ - mice. (a) Quantitative real-time PCR (qRT-PCR) analysis of Rorc and II23r on the indicated thymocytes of Rorc $+/+$ mice at day 5. (b) Left: Gross anatomic images showing the size of a representative thymus of WT $\left(\right.$ Rorc $\left.^{+/+}\right)$or Rorc ${ }^{+/-}$mice at day 9 . Right: Flow cytometry analysis of CD4 and CD8 on total thymocytes (Thy1.2 ${ }^{+}$). The frequency of CD4 ${ }^{+} \mathrm{CD} 8{ }^{+}$cells within the total Thy $1.2^{+}$thymocytes is indicated. Scale bar, 3.0 mm. (c) qRT-PCR analysis of $1123 \mathrm{r}$ on the indicated thymocyte subpopulations from the indicated mouse strains at day 5. (d) qRT-PCR analysis of the expression of $c-R e l$ and $B C l-x l$ in the indicated thymocyte subpopulations at day 5. Data in (a-d) are representative of three independent experiments (mean \pm s.e.m., $N=3-5$ mice per group; ${ }^{\star \star} P<0.01,{ }^{\star \star \star} P<0.005$ between AdLacZ and AdlL-23-treated or Rorc ${ }^{+/}-$and Rorc ${ }^{+/+}$mice).

spleen cells from B6 female or male mice in the presence and absence of IL-23. Depletion of $\mathrm{CD} 4^{+} \mathrm{CD}^{+}$thymocytes and expression levels of ROR $\gamma t$ in the thymocytes cultured with irradiated female spleen stimulator cells did not differ with or without IL-23, presumably because the thymocytes lacked IL-23R induced by specific Ag stimulation (Fig. 7f). In contrast, coculture of thymocytes from female $\mathrm{D}^{\mathrm{b}} / \mathrm{H}-\mathrm{Y}$ TCR Tg mice with irradiated spleen cells from $\mathrm{B} 6$ male mice resulted in a significant upregulation of IL-23R, increased expression of ROR $\gamma \mathrm{t}$ and increased apoptosis. Furthermore, addition of IL-23 further upregulated both IL-23R and ROR $\gamma$ t and greatly enhanced apoptosis (Fig. 7f). Similar results were observed after co-culture of MHC class II restricted $\mathrm{MOG}_{35-55}$-reactive thymocytes from 2D2 TCR Tg mice with MOG-pulsed irradiated spleen cells in the presence of IL-23 (Supplementary Fig. 10).

IL-23 preferentially eliminates natural occurring Treg thymocytes. One puzzle is the action of IL-23-mediated deletion of selfreactive $\mathrm{T}$ cells in the thymus seem to be in opposition to its well known proinflammatory role in the different autoimmune diseases $^{23,24,40}$. We thus used Foxp3-GFP mice to track the percent of Foxp $^{+}{ }^{+} \mathrm{Helio}^{+}$natural occurring Treg (nTreg) cells after AdIL-23 administration. There was a significant reduction of nTregs in CD4 SP cells in the thymus (Supplementary Fig. 11) in the AdIL-23-administered group, comparing with AdLacZ-treated control group. Consistent with these findings, following AdIL-23 administration, in the spleens of WT CD45.1: Il23r- ${ }^{-}$- CD45.2 mixed BM-reconstituted mice, the nTreg population was primarily Il23r-/- CD 45.2 cells, whereas the Th17s were primarily from Il23r ${ }^{+/+}$CD45.1 origin (Supplementary Fig. 12a-f). These data are consistent with recent studies that high levels of IL-23 was associated with increasing Th17s $\mathrm{s}^{40-42}$ and reduced Tregs ${ }^{40,43}$. IL-23 elimination of nTregs in the thymus may therefore act in concert with IL-23 in the periphery to promote autoimmune disease.

\section{Discussion}

Our present study advances the present understanding of IL-23 and negative selection in that it implicates IL-23 mediates apoptosis during the process of negative selection in the thymus. The current concept of negative selection is that the induction of apoptosis during negative selection is driven by direct cell contact between the self-antigen-presenting cells and the thymocytes expressing self-reactive TCRs (ref. 44). It has been shown that the process of negative selection is less stringent than positive selection because negative selection is never $100 \%$ complete and is always associated with some leakage of self-reactive $\mathrm{T}$ cells ${ }^{45}$. The present findings are consistent with this variability in that they indicate that while the cell-cell interactions define the specificity of negative selection, IL-23 signalling can act as a second 

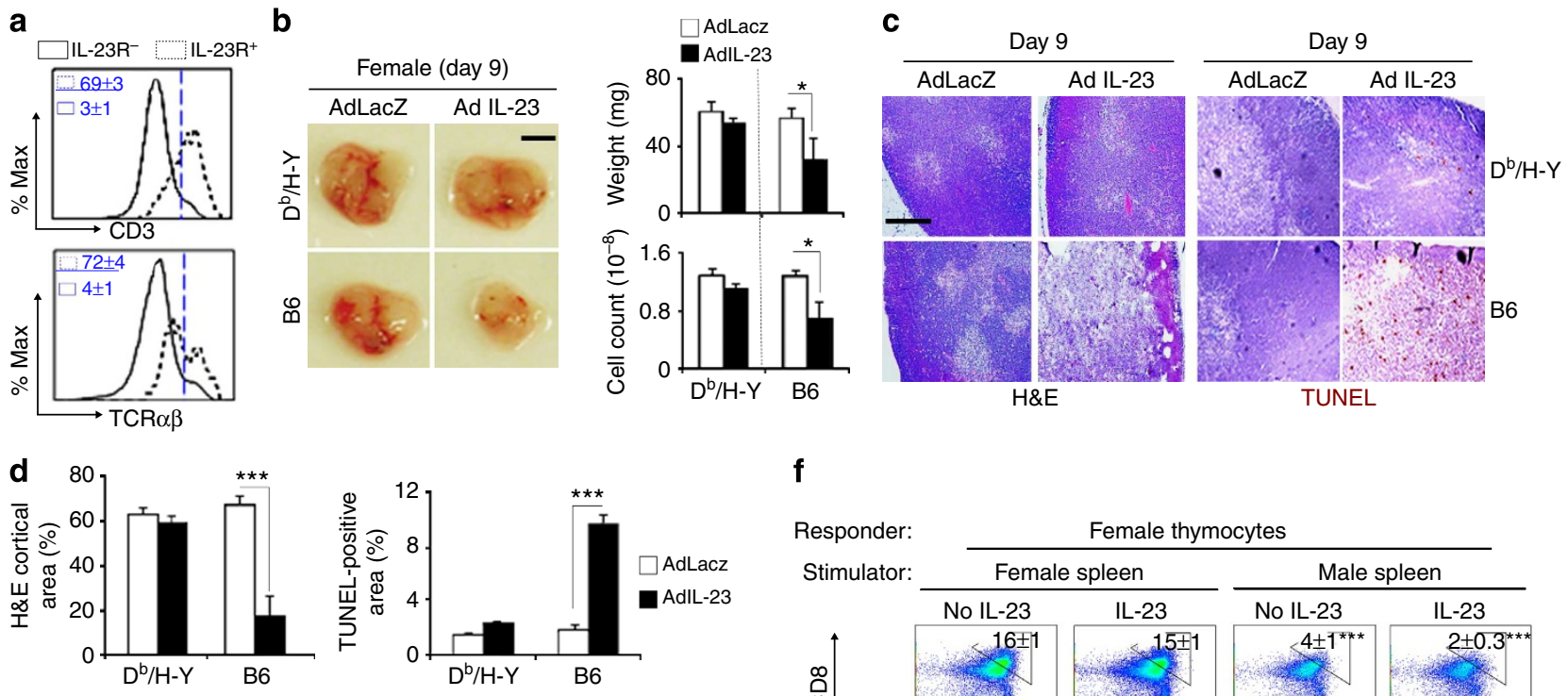

f

e

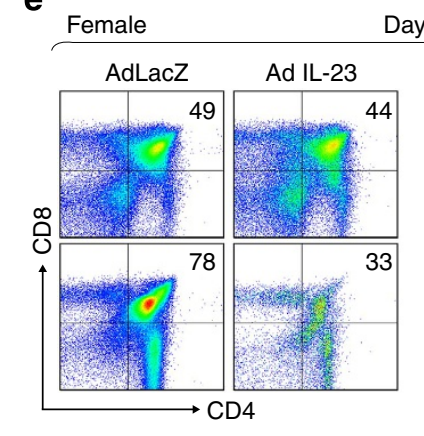

Day 9

$\mathrm{CD} 4^{\mathrm{lo}} \mathrm{CD} 8^{\mathrm{lo}} \mathrm{CD} 4^{\mathrm{hi}} \mathrm{CD} 8^{\mathrm{hi}}$

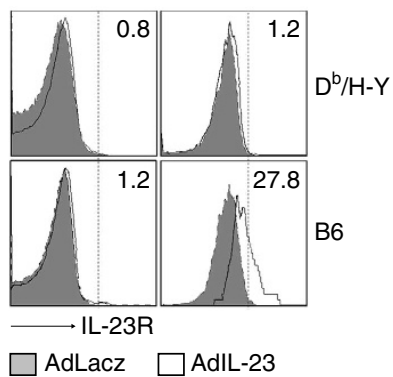

Responder:

Stimulator:

Female thymocytes
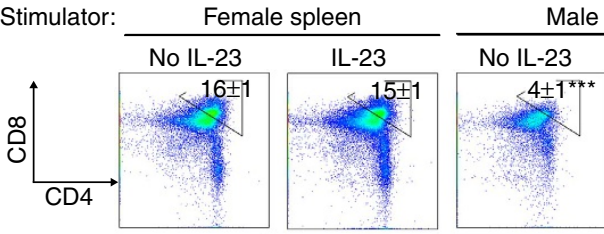

ale spleen
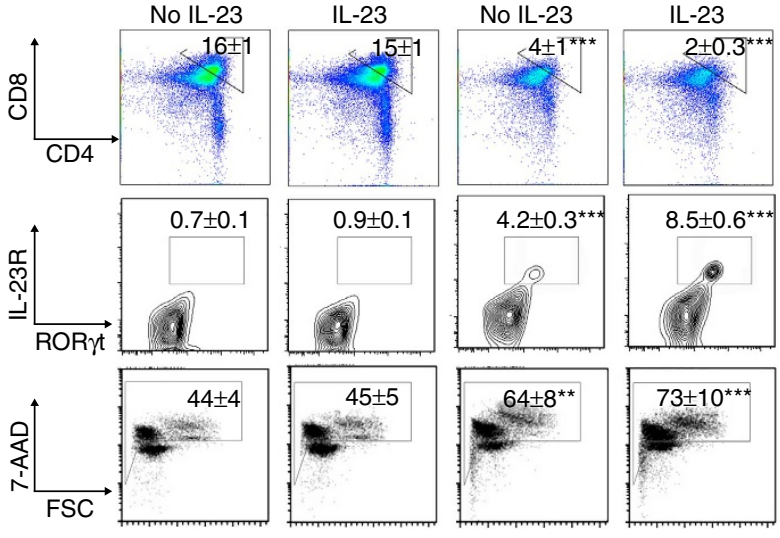

Figure 7 | Antigen activation initiates the expression of IL-23R on CD4 ${ }^{\text {hicD }}$ ( $^{\text {hiDP }}$ thymocytes. (a) Flow cytometry analysis of the expression of $\alpha \beta T C R$ and $\mathrm{CD} 3 \epsilon$ on $\mathrm{IL}-23 \mathrm{R}^{+} \mathrm{CD} 4{ }^{+} \mathrm{CD} 8+$ or $\mathrm{IL}-23 \mathrm{R}^{-} \mathrm{CD} 4{ }^{+} \mathrm{CD} 8+$ thymocytes from naïve $\mathrm{C57L/B6J}$ mice. The percentage of $\alpha \beta T C R{ }^{+}$or $\mathrm{CD} 3 \epsilon$ cells in the indicated population is shown. (b-e) Female $D^{\mathrm{b}} / \mathrm{H}-\mathrm{Y}$ TCR Tg mice and female C57L/B6J mice were injected with either AdIL-23 or AdLacZ. Mice were killed at day 9. (b) Left: Gross anatomic images showing the size of a representative thymus of the indicated mouse strains. Right: The weight and cellularity are shown. Scale bars, $3.0 \mathrm{~mm}$. (c) In situ hematoxylin and eosin (H\&E) (left) and in situ TUNEL staining (dark brown) (right) of a representative thymus section from the indicated group. The magnification of objective lens is $\times 10 \times$. Scale bars, $300 \mu \mathrm{m}$. (d) BioQuant quantification of the frequency of thymic cortical area (left) or the frequency of TUNEL-positive area (right) from 10 randomly chosen areas. The results represent mean \pm s.e.m. $(N=2-3$ per group for two independent experiments, ${ }^{\star} P<0.05,{ }^{\star \star} P<0.01,{ }^{\star \star \star} P<0.005$ for the indicated sample compared with AdLacZ injected group). (e) Left: Flow cytometry analysis of CD4 and CD8 expression on Thy $1.2^{+}$cells in the indicated group. The percent of CD4 ${ }^{+}$CD $8{ }^{+}$cells is shown. Right: Flow cytometry analysis of IL-23R on $\mathrm{CD} 4^{\mathrm{lo}} \mathrm{CD} 8^{\mathrm{lo}}$ and $\mathrm{CD} 4^{\mathrm{hi}} \mathrm{CD} 8^{\text {hi }}$ thymocytes. The percentage of IL-23R ${ }^{+}$cells is indicated. (f) Thymocytes from female $\mathrm{D}^{\mathrm{b}} / \mathrm{H}-\mathrm{Y}$ mice were co-cultured in vitro with irradiated female or male splenocytes from Thy $1.1 \mathrm{C} 57 \mathrm{BL} / 6$ in the presence or absence of exogenous mouse recombinant IL-23. Top: Flow cytometry analysis of CD4 and CD8 expression on Thy $1.2^{+}$cells in the indicated group. The percent of CD $4^{\text {hi }} C D 8^{\text {hi }}$ cells is shown; Middle: The expression of IL-23R and ROR $\gamma$ t on gated Thy $1.2^{+} \mathrm{CD} 4{ }^{+} \mathrm{CD} 8{ }^{+}$cells is shown; bottom: analysis of apoptosis (7-amino actinomycin D (7-AAD)) in Thy $1.2^{+} \mathrm{CD} 4{ }^{+} \mathrm{CD} 8{ }^{+}$cells. The percent of apoptotic cells is shown $\left(N=3-4\right.$ mice per group for two independent experiments; ${ }^{\star} P<0.05,{ }^{\star \star} P<0.01$, ${ }^{\star \star \star} P<0.005$ between thymocytes stimulated with female spleen cells in the absence of IL-23 compared with the indicated group).

regulatory mechanism that defines the susceptibility of the interacting thymocytes to undergo apoptosis. The current studies do not rule out the possibility that, under some circumstances, higher affinity cell interactions may result in apoptosis in the absence of IL-23 or other cytokine signalling but do suggest that strong IL-23 signalling acts as adjuvant effects to downregulate the threshold of TCR-mediated apoptosis and promotes the elimination of a great proportion of potentially self-reactive thymocytes.

The present results suggest that the IL-23-mediated thymocyte apoptosis is under both temporal and spatial regulation. The IL-23 specifically targets the $\mathrm{CD} 4^{\text {hi }} \mathrm{CD} 8^{\text {hi }} \mathrm{CD} 3^{+} \alpha \beta \mathrm{TCR}^{+}$latestage DP thymocyte subset in naïve mice and this highly specific targeting appears to be enforced through several mechanisms. IL-23R expression is limited to a small subset of thymocytes that are phenotypically identical to late-stage DP thymocytes. Within this population, its expression is induced by TCR engagement, suggesting that the interactions with the DCs are a triggering mechanism, and are subsequently enhanced by endogenous IL-23. Moreover, the downstream target of IL-23 signalling of apoptosis is ROR $\gamma \mathrm{t}$, a thymus-specific isoform of $\operatorname{ROR} \gamma$, which is expressed predominantly in DP thymocytes ${ }^{46}$. ROR $\gamma$ t activates the gene encoding the anti-apoptotic protein $\mathrm{Bcl}-\mathrm{xL}$ and which has been shown to be required for the survival of early DP thymocytes ${ }^{10}$. Paradoxically, enforced expression of ROR $\gamma \mathrm{t}$ also lead to dramatic reduction of DP thymocytes ${ }^{46}$. The present findings unify these two apparently contradictory results and directly demonstrate that preferential expression of IL-23R in the late versus early DP thymocytes along with the migration of late DP thymocytes to the IL-23 producing thymic DC area in the 
medulla lead to differential ROR $\gamma$ t-mediated apoptosis versus survival. Furthermore, the IL-23/ROR $\gamma \mathrm{t}$-mediated late DP thymocyte apoptosis does not affect the expression of $B c l-x l$ but is associated with a significant decline in $c$-Rel. Interestingly, a relatively small change in Rorc was found to exhibit remarkable impact on IL-23R-mediated thymocyte apoptosis. Such results underscore the importance in fine-tuning the expression of Rorc in regulating $\mathrm{IL}^{-23}{ }^{+} \mathrm{TCR}$ signalling-induced late-stage $\mathrm{DP}$ thymocyte apoptosis.

Induction of thymocyte apoptosis by IL-23 overexpression required IL-23R expression, as apoptosis was not increased in treated $\mathrm{Il} 23 \mathrm{r}^{-/-}$mice. Although IL-23R were expressed on different types of cells, the requirement for IL-23R expression on thymocytes but not non-thymocytes for the most efficient IL-23induced apoptosis was shown by BM reconstitution of CD45.2 Il23r-/- mice with BM from CD45.1 WT mice. Furthermore, in IL-23R-intact mice, 5 days after AdIL-23 administration, IL-23R was highly upregulated on $\mathrm{CD} 4^{\mathrm{hi}} \mathrm{CD} 8^{\mathrm{hi}}$ thymocytes, which correlates with the peak levels of IL-23 in the sera and the initial loss of $\mathrm{CD} 4{ }^{\text {hi }} \mathrm{CD} 8^{\text {hi }}$ thymocytes. Although IL-23R is predominantly expressed on $\mathrm{CD} 4^{\mathrm{hi}} \mathrm{CD} 8^{\text {hi }}$ thymocytes, on subsequent days, there was extensive reduction of both $\mathrm{CD} 4{ }^{\mathrm{hi}} \mathrm{CD} 8^{\mathrm{hi}}$ and $\mathrm{CD} 4{ }^{\mathrm{lo}} \mathrm{CD} 8{ }^{\mathrm{lo}}$ thymocytes. We proposed that the loss of $\mathrm{CD} 4{ }^{\mathrm{hi}} \mathrm{CD} 8{ }^{\text {hi }}$ thymocytes promoted the maturation of $\mathrm{CD} 4^{\text {lo }} \mathrm{CD} 88^{\text {lo }}$ thymocytes to $\mathrm{CD} 4^{\mathrm{hi}} \mathrm{CD} 88^{\text {hi }}$ thymocytes, which then undergo rapid apoptosis mediated by IL-23. This is supported by the observation that on day 9 after AdIL-23, IL-23R expression colocalized with TUNEL staining, indicating that IL-23R ${ }^{+}$ thymocytes underwent apoptosis. Taken together, we conclude that IL-23 directly induces apoptosis of late-stage DP thymocytes subpopulation.

One unexpected finding is the complexity of IL-23R induction and expression on thymocytes. Induction of IL-23R on $\mathrm{CD} 4{ }^{\mathrm{hi}} \mathrm{CD} 88^{\mathrm{hi}}$ thymocytes requires antigen stimulation. IL-23R upregulation and the following apoptosis progress were not observed in AdIL-23-treated $\mathrm{D}^{\mathrm{b}} / \mathrm{H}-\mathrm{Y}$ TCR Tg female mice due to the lack of $\mathrm{H}-\mathrm{Y}$ male antigen stimulations. The requirement of TCR engagement for induction of IL-23R was further demonstrated in vitro by co-culture of thymocytes from MHC class I $\left(\mathrm{D}^{\mathrm{b}} / \mathrm{H}-\mathrm{Y}\right.$, female) or class II (2D2) TCR Tg mice with cells presenting $\mathrm{D}^{\mathrm{b}} / \mathrm{H}-\mathrm{Y}$ or $\mathrm{H} 2^{\mathrm{b}} / \mathrm{MOG}_{35-55}$ antigen, respectively. However, analysis of IL-23R on DN thymocytes in $\mathrm{D}^{\mathrm{b}} / \mathrm{H}-\mathrm{Y}$ TCR Tg male mice shows that despite the early assembling of selfreactive TCR, IL-23R expression is still low, suggesting that assembled TCR complex is required but is not sufficient to induce IL-23-mediated thymocyte apoptosis. A second requirement is signalling through the IL-23R/ROR $\gamma \mathrm{t}$ pathway that forms a positive feedback loop since IL-23R expression was diminished in Rorc $^{+1-}$ heterozygote mice compared with Rorc $^{+1+}$ homozygote mice. Thymocyte co-culture in the presence of IL-23 plus self $\mathrm{Ag}$ in vitro resulted in further upregulation of IL-23R/ROR $\gamma \mathrm{t}$ signalling, which lead to IL-23-mediated apoptosis. We therefore propose that under naïve condition, engagement of the TCR complex by self-antigen is a key predisposing factor and IL-23 may act as a second regulatory mechanism to enhance the susceptibility of weakly self-reactive $\mathrm{CD} 4{ }^{\text {hi }} \mathrm{CD} 8^{\text {hi }}$ late-stage DP thymocytes to apoptosis.

Most thymic cells are able to produce cytokines either spontaneously or after stimulation ${ }^{47}$. Various groups have demonstrated previously that the production of cytokines, such as IL-7 (refs 48,49 ) by thymic epithelial cells, IL-12 (ref. 50) by thymic DCs as well as IFN $\gamma^{51,52}$, IL-4 (refs 53-55) and IL-2 (refs 12,56) by thymocytes, affects thymocyte development and differentiation. Significant reduction of DP thymocytes was also reported previously under other inflammatory conditions including dextran sulphate sodium-induced colitis ${ }^{57-59}$. We do not completely rule out the involvement of other cytokines in the massive apoptosis found in A. fumigatus-infected mice, although the results suggested that IL-23, in combination with TCR signalling that occurs at the $\mathrm{CD} 4^{\mathrm{hi}} \mathrm{CD} 8^{\mathrm{hi}}$ late stage of $\mathrm{DP}$ thymocyte development, plays an important role in this process. Increasing evidence suggests that thymic conventional DCs but not plasmacytoid DCs cross-present self-Ags to develop thymocytes and play an important role in thymocyte negative selection and central tolerance induction. All these are consistent with recent finding that $\mathrm{CD} 103^{+}$DCs are the major source of intrathymic IL-23 (ref. 60).

Our data show for the first time that IL-23 is involved in thymic negative selection. How this process affects multiple cells in the periphery of the host in resolving fungal infection is not precisely known. However, as IL-23R signalling in $\mathrm{CD} 4{ }^{+} \mathrm{T}$ cells induces effector $\mathrm{T}_{\mathrm{H}^{-1}}$ (refs 61,62) and suppresses regulatory $\mathrm{CD} 4{ }^{+} \mathrm{T}$ cells ${ }^{40}$ in the periphery, our findings suggest a potential IL-23-mediated central immune regulation mechanism that may promote inflammation by limiting thymic regulatory $\mathrm{T}$-cell output. Increased understanding of this process may lead to novel approaches beneficial for control of infection and systemic autoimmune diseases.

\section{Methods}

Mice. Il23 $\mathrm{p} 19^{-/-}$mice were obtained from Merck Research Laboratory (Palo Alto, CA $)^{24,25}$. The IL-23R-GFP KI mouse and the homozygous Il23r-/mouse were obtained from the Department of Pediatrics, University of Washington, Seattle, WA ${ }^{36}$. WT B6, B6 C.Cg-Foxp $3^{\text {tm2Tch }} / \mathrm{J}$ and B6.129P2(Cg)Rorc $^{t m 2 L i t t} / \mathrm{J}^{63}$ mice were obtained from Jackson Laboratory (Bar Harbor, ME) and $\mathrm{D}^{\mathrm{b}} / \mathrm{H}-\mathrm{Y}$ Tg from Taconic Farms (Hudson, NY). C57BL/6 CD45.1 (Ly5.1) mice were purchased from the UAB Gnotobiotic Facility. All mice were kept in the animal facilities of University of Alabama at Birmingham, AL, under specific pathogen-free conditions until used for the experiments. All experiments conducted in this study have been reviewed and approved by the institutional animal care and use committee of University of Alabama at Birmingham. All mice were 6-12-week-old female unless otherwise indicated.

Preparation of A. fumigatus and in vivo challenge. A. fumigatus isolate 13073 was cultured on potato dextrose agar at $37^{\circ} \mathrm{C}$ for 7 days, collected with a cell scraper and enumerated using a hemocytometer. $5 \times 10^{7}$ A. fumigatus conidia were administrated to each mouse in a volume of $100 \mu \mathrm{l}$ by intraperitoneal injection.

BM transplantation. Indicated recipients were sublethally $\gamma$-irradiated ( 320 rads) and reconstituted with indicated donor BM cells. BM cells from donor mice $\left(2 \times 10^{7}\right)$ were injected into each recipient mouse by intravenous (i.v.) administration $30 \mathrm{~min}$ after irradiation. After irradiation, the mice are kept on acidic, antibiotic water for 2 weeks (water is first adjusted to $\mathrm{pH} 2.6$ with concentrated $\mathrm{HCl}$ and autoclaved in $1 \mathrm{~L}$ bottles. Then, to $1 \mathrm{~L}$ of acidic $\mathrm{H}_{2} \mathrm{O}, 10 \mathrm{ml}$ of $10 \mathrm{mg} \mathrm{ml}^{-1}$ neomycin in saline (Sigma N112, $20 \mathrm{ml}$ vials) was added. Animals were allowed to recover for at least 5 weeks.

Administration of adenovirus and z-VAD. For the AdIL-23 producing high expression of IL-23 and the control AdLacZ, AdIL-23 $\left(2 \times 10^{9}\right.$ p.f.u. per mouse; a generous gift from Dr Jay K. Kolls at the Louisiana State University Health Sciences Center made by Dr Euan Lockhart $)^{34,35}$ or AdLacZ $\left(2 \times 10^{9}\right.$ p.f.u. per mouse) was administered i.v. $z$-VAD $(200 \mu \mathrm{g}$ per mouse, $R \& D, M N)$ was given by i.v. injection $24 \mathrm{~h}$ after AdIL-23 administration.

Thymus collection and cell count. The thymus was removed and immediately placed in RPMI 1640 medium. Thymi were photographed using a Cool PIX990 digital camera (Nikon, Tokyo, Japan). Single-cell suspensions were obtained after $1 \%$ collagenase D (Roche Applied Science, Indianapolis, IN) digestion of whole thymi at $37^{\circ} \mathrm{C}$ for $30 \mathrm{~min}$. Thymocyte count was determined using a Cellometer Auto T4 Plus Cell Counter (Nexcelom Biosciences LLC, Lawrence, MA).

Flow cytometry analysis. Single-cell suspensions of thymocytes were analysed by flow cytometry using combinations of PE-Cy7 anti-mouse CD90.2 (Thy1.2) (1:400 dilution, clone 53-2.1), A700 or APC-anti-CD4 (1:400 dilution, clone H129.19), PE-anti-mouse H-Y TCR (1: 200 dilution, clone T3.70, eBioscience, San Diego, CA), pacific blue anti-mouse CD8 (1:400 dilution, clone 53-6.7), PE-anti-mouse/human Foxp3 (1:50 dilution, clone 150D), APC-anti-mouse/ human Helios (1:50 dilution, clone 22F6), Biotin anti-mouse CD3€ antibody (1:400 
dilution, clone 145-2C11), Biotin anti-mouse TCR $\alpha \beta$ (1:400 dilution, clone WT31, BD Pharmingen, San Diego, CA), Biotin-conjugated anti-CD11c (1:100 dilution, clone N418), APC-anti-human/mouse ROR $\gamma \mathrm{t}$ (1:100 dilution, clone AFKJS-9, eBioscience) and Anti-IL-23R antibody as primary antibody (1:100 dilution, goat polyclonal to IL23 receptor, Abcam, CA), Alexa Fluor 488 donkey anti-goat IgG $(\mathrm{H}+\mathrm{L})$ (1:200 dilution, Invitrogen, CA) as secondary antibody for IL-23R staining. Unless specified, all antibodies used for FACS staining were obtained from BioLegend (San Diego, CA). Single-cell suspensions of thymocytes were washed once with FACS buffer ( $5 \%$ fetal calf serum and $0.1 \%$ sodium azide in phosphatebuffered saline (PBS)), and incubated first with unconjugated anti-CD16/CD32 (1:200 dilution, Fc Block; BD Pharmingen) at room temperature for $20 \mathrm{~min}$. Cells were then incubated with a biotin-conjugated $\mathrm{Ab}$ at room temperature for $20 \mathrm{~min}$ and washed once with FACS buffer. Second-step incubations were performed at room temperature for $20 \mathrm{~min}$ with pacific blue, APC-Cy7-streptavidin, PE-, Cy7-, APC- and fluorescein isothiocyanate-conjugated Abs. Intracellular staining for ROR $\gamma \mathrm{t}$ was performed using the one-step kit for nuclear proteins (eBioscience). After staining, the cells were washed twice with FACS buffer and staining stored in PBS containing 2\% paraformaldehyde until FACS analysis. Cells (300,000 per sample) were analysed on an LSRII Flow Cytometry Analyzer (BD Biosciences, Franklin Lakes, NJ).

Histology analysis. The thymi were removed from the mice immediately after killing, fixed in $10 \%$ phosphate-buffered formalin ( $\mathrm{pH} 7.0)$ and embedded in paraffin. Thin tissue sections $(7 \mathrm{~nm})$ were cut, deparaffinated and stained with hematoxylin and eosin.

Immunohistochemical staining. Tissue samples of the thymi of killed mice were collected and fixed in 10\% neutral formalin. Before paraffin sections obtained were stained, endogenous peroxidase activity was suppressed by incubating the slides in $3 \% \mathrm{H}_{2} \mathrm{O}_{2}$ for $5 \mathrm{~min}$. Sections were incubated in PBS buffer containing $1 \%$ BSA, $1 \mathrm{mM}$ EDTA and $0.15 \mathrm{mM} \mathrm{NaN3}$, pH 7.6 with $1 \%$ goat serum for 20 min to reduce nonspecific staining. The sections were then incubated for $60 \mathrm{~min}$ with the purified rat anti-mouse S100 (1:50 dilution, Clone 6G1, BD Biosciences) diluted in PBE buffer. The secondary reagents were revealed using streptavidin peroxidase (Signet Laboratories, Dedham, MA), which was applied for $20 \mathrm{~min}$. The diaminobenzidine substrate reagent (BioGenex, San Ramon, CA) was prepared immediately before use and applied for $7 \mathrm{~min}$. The stained sections were lightly counterstained with hematoxylin before mounting. In all cases, negative controls, consisting of incubations without the primary $\mathrm{Ab}$, were included in the analyses.

TUNEL staining. TUNEL staining was performed using an ApopTag In Situ Apoptosis Staining kit on paraffin-embedded sections (Serologicals, Norcross, $\mathrm{GA})^{63,64}$. Deparaffinized tissues were quenched in $3.0 \%$ hydrogen peroxide for endogenous peroxidase first and then incubate in a humidified chamber at $37^{\circ} \mathrm{C}$ for $1 \mathrm{~h}$ with Working Strength TdT Enzyme. Anti-digoxigenin conjugate and peroxidase substrate were applied separately for $30 \mathrm{~min}$ before mounting.

Ki67 staining. Thymi were collected and fixed in 10\% neutral formalin. Paraffin sections obtained were stained with primary antibodies for Ki67 (1:50 dilution, Laboratory Vision Corporation, Fremont, California). The slides were heated in a $10 \mathrm{mM}$ EDTA solution at $\mathrm{pH} 8$ in a pressure cooker for $10 \mathrm{~min}$ and then cooled slowly. Negative controls were performed by omitting the primary antibodies. Secondary detection was accomplished using a multispecies detection system (Signet Laboratories). The sections were exposed to a biotinylated anti-mouse antibody (1:100 dilution) for $20 \mathrm{~min}$ and then peroxidase-labelled streptavidin (1:100 dilution) was added for $20 \mathrm{~min}$. A diaminobenzidine tetrachloride supersensitive substrate kit (BioGenex) was used to visualize the antibody-antigen complex. Each section was counterstained using a weak Myer's hematoxylin, dehydrated using graded alcohols and soaked in xylene baths.

Frozen fluorescence staining. Tissue samples of the thymi of killed mice were embedded in Histo-Prep frozen tissue-embedding medium (Fisher Scientific, Fair Lawn, NJ) and snap-frozen on dry ice. Frozen sections of thymic tissue were fixed in acetone for 15 min before staining. Sections were incubated in PBE buffer (PBS containing $1 \% \mathrm{BSA}, 1 \mathrm{mM}$ EDTA, and $0.15 \mathrm{mM} \mathrm{NaN3}$, pH 7.6) with $1 \%$ horse serum for $20 \mathrm{~min}$ to reduce nonspecific staining. The sections were then incubated for 30 min with A647 anti-CD90.2 (1:100 dilution, clone 30-H12, BioLegend) and purified anti-EpCAM (clone G8.8, eBioscience) conjugated with A555 by APEX Alex Fluor 555 Antibody Labelling Kit (Invitrogen, CA). In all cases, negative controls, consisting of incubations without the primary $\mathrm{Ab}$, were included in the analyses.

Histomorphometry quantitation. BioQuant Image Analysis software (R\&M Biometrics, Nashville, TN) was used for histomorphometrical analyses as we previously described ${ }^{24}$. On hematoxylin and eosin-stained sections (at $\times 5$ ), area measurements were made of the total tissue area (area enclosed by the outline of the whole section), cortical area and medullary area (areas distinguished by the difference of the histological appearance and stained colour). Percentages of cortical area and medullary area per total tissue area were calculated using the formula: (cortical area/total tissue area) $\times 100$; and (medullary area/total tissue area) $\times 100$. On TUNEL and Ki67 immunohistochemistry stained sections (at $\times 5$ ), area measurements were made of the total tissue areas (area enclosed by the outline of the TUNEL-stained section or Ki67-stained section), TUNEL positive and Ki67-positive areas (areas measured by picking the pixels with brown colour from diaminobenzidine chromogen on both sections, using BioQuant's thresholding tool). Percentages of $\mathrm{TUNEL}^{+}$and $\mathrm{Ki}^{+} 7^{+}$area per total tissue area were calculated using the formula: (TUNEL ${ }^{+}$area/total tissue area) $\times 100$, and $\left(\mathrm{Ki}^{+} 7^{+}\right.$area/total tissue area) $\times 100$.

SYBR green real-time quantitative real-time PCR analysis. RNA isolated from the thymus of 2-month-old mice (five samples per group) was used to construct cDNA using the Maxima First Strand cDNA Synthesis Kit (Fermentas, Glen Burnie, MD). The sequence of the primers used were: $B c l-x l$ sense: $5^{\prime}$-GAGCAG GTAGTGAATGAAC- $3^{\prime}, B c l$ - $x l$ anti-sense: $5^{\prime}$-GATCCAAGGCTCTAGGTG- $3^{\prime} ; I l 2$ sense: $5^{\prime}$-GAAGGCTATCCATCTCCTCAG-3', $c$-Rel anti-sense: $5^{\prime}$-CCTGACACT TCCACAGTTCTTG-3'; Il23 sense: 5'-AGTGTGAAGATGGTTGTGAC-3' ${ }^{\prime}$ Il23 anti-sense: $5^{\prime}$-CTGGAGGAGTTGGCTGAG- $3^{\prime}$; $I l 23 r$ sense: $5^{\prime}$-CACTGCTGAAT GAATGTCCTGGTC- $3^{\prime}$; $I l 23 r$ anti-sense: $5^{\prime}$-GGTATCTATGTAGGTAGGCT TCC-3'; Rorc sense: $5^{\prime}$-TTCTCATCAATGCCAACCG- $3^{\prime}$, Rorc anti-sense: $5^{\prime}$-GCC AGTTCCAAATTGTATTGC-3'; Gapdh sense: $5^{\prime}$-AGGTCGGTGTGAACGGAT TTG-3', Gapdh anti-sense: 5'-TGTAGACCATGTAGTTGAGGTCA-3'. All probes were designed to span an intron to prevent amplification of DNA potentially present in the sample.

In each run, a series of 10 -fold dilutions of a single standard cDNA derived from a positive control mouse RNA (Stratagene, La Jolla, CA) were amplified to create a standard curve, and values of unknown samples were estimated relative to this standard curve. Replicate dilutions of the unknown sample cDNAs from $40 \mathrm{ng}$ of total RNA were combined with a mixture of primers, iQ SYBR Green Supermix with Taq polymerase, and nucleotides (Bio-Rad). Each sample (total volume, $25 \mu \mathrm{l}$ ) was assayed in an optical tube designed for the 96-well format for the IQ5 Thermocycler (Bio-Rad). Each PCR amplification was performed in duplicate using the following conditions: $5 \mathrm{~min}$ at $94^{\circ} \mathrm{C}$, followed by a total of 40 cycles $(15 \mathrm{~s}$ at $94^{\circ} \mathrm{C}$ and $30 \mathrm{~s}$ at $55^{\circ} \mathrm{C}$ ). Each PCR was run in duplicate. The mean value of the two reactions was defined as representative of the sample. The volumes described above yielded standard curves with a linear relationship between the copy numbers of the original internal standard added and the number of PCR cycles required to exceed a preset threshold according to the method described by Dreskin et al ${ }^{65}$ From these standard curves, the relative amount of cDNA for the house keeping gene Gapdh and the relative amount of cDNA for each gene were determined for each sample.

Thymocyte stimulation assay. Thymocytes were cultured in triplicate with IL-2 ( $5 \mathrm{ng} \mathrm{ml}^{-1}$, eBioscience) and IL-7 (5 $\left.\mathrm{ng} \mathrm{ml}^{-1}, \mathrm{R} \& \mathrm{D}\right)$, with or without purified mouse rIL-23 (R\&D, $\left.20 \mathrm{ng} \mathrm{ml}^{-1}\right)$ or irradiated (3,200 rads) splenocytes from male or female Thyl.1 mice as stimulator (ratio: stimulators/responders $=1 / 3$ ) for $20 \mathrm{~h}$ Flow cytometry analysis was performed for the expression of the indicated markers. Apoptosis was quantitated using 7 -amino actinomycin D staining and was accessed by flow cytometry ${ }^{51}$.

Statistical analysis. The values are reported as the mean of each group \pm s.e.m. Statistical analyses were performed using Student's unpaired two-tailed $t$-test. A value of $P<0.05$ was considered statistically significant.

\section{References}

1. Saito, T. \& Watanabe, N. Positive and negative thymocyte selection. Crit. Rev. Immunol. 18, 359-370 (1998).

2. Bouvier, G. et al. Deletion of the mouse T-cell receptor beta gene enhancer blocks alphabeta T-cell development. Proc. Natl Acad. Sci. USA 93, 7877-7881 (1996).

3. Fowlkes, B. J., Schwartz, R. H. \& Pardoll, D. M. Deletion of self-reactive thymocytes occurs at a CD $4+8+$ precursor stage. Nature 334, 620-623 (1988).

4. White, H. \& Bergmann, G. Localization in near-monolayer films. Phys. Rev. B Condens. Matter. 40, 11594-11602 (1989).

5. Wu, L. \& Shortman, K. Heterogeneity of thymic dendritic cells. Semin. Immunol. 17, 304-312 (2005).

6. Goldschneider, I. \& Cone, R. E. A central role for peripheral dendritic cells in the induction of acquired thymic tolerance. Trends Immunol. 24, 77-81 (2003).

7. Heino, M. et al. RNA and protein expression of the murine autoimmune regulator gene (Aire) in normal, RelB-deficient and in NOD mouse. Eur. J. Immunol. 30, 1884-1893 (2000).

8. He, Y. W., Deftos, M. L., Ojala, E. W. \& Bevan, M. J. RORgamma t, a novel isoform of an orphan receptor, negatively regulates Fas ligand expression and IL-2 production in T cells. Immunity 9, 797-806 (1998). 
9. Kurebayashi, S. et al. Retinoid-related orphan receptor gamma (RORgamma) is essential for lymphoid organogenesis and controls apoptosis during thymopoiesis. Proc. Natl Acad. Sci. USA 97, 10132-10137 (2000).

10. Sun, Z. et al. Requirement for RORgamma in thymocyte survival and lymphoid organ development. Science 288, 2369-2373 (2000).

11. Littman, D. R. et al. Role of the nuclear hormone receptor ROR gamma in transcriptional regulation, thymocyte survival, and lymphoid organogenesis. Cold Spring Harb. Symp. Quant. Biol. 64, 373-381 (1999).

12. Bassiri, H. \& Carding, S. R. A requirement for IL-2/IL-2 receptor signaling in intrathymic negative selection. J. Immunol. 166, 5945-5954 (2001).

13. Liou, H. C. \& Smith, K. A. The roles of c-rel and interleukin-2 in tolerance: a molecular explanation of self-nonself discrimination. Immunol. Cell Biol. 89, 27-32 (2011).

14. He, Y. W. et al. Down-regulation of the orphan nuclear receptor ROR gamma $t$ is essential for T lymphocyte maturation. J. Immunol. 164, 5668-5674 (2000).

15. Oppmann, B. et al. Novel p19 protein engages IL-12p40 to form a cytokine, IL-23, with biological activities similar as well as distinct from IL-12. Immunity 13, 715-725 (2000)

16. Kastelein, R. A., Hunter, C. A. \& Cua, D. J. Discovery and biology of IL-23 and IL-27: related but functionally distinct regulators of inflammation. Annu. Rev. Immunol. 25, 221-242 (2007).

17. Tato, C. M. \& Cua, D. J. Reconciling id, ego, and superego within interleukin23. Immunol. Rev. 226, 103-111 (2008).

18. Ivanov, I. I. et al. The orphan nuclear receptor RORgammat directs the differentiation program of proinflammatory IL-17+ T helper cells. Cell 126, 1121-1133 (2006).

19. Wilson, N. J. et al. Development, cytokine profile and function of human interleukin 17-producing helper T cells. Nat. Immunol. 8, 950-957 (2007).

20. Werner, J. L. et al. Neutrophils produce interleukin 17A (IL-17A) in a dectin-1and IL-23-dependent manner during invasive fungal infection. Infect. Immun. 79, 3966-3977 (2011)

21. Gessner, M. A. et al. Dectin-1-dependent interleukin-22 contributes to early innate lung defense against Aspergillus fumigatus. Infect. Immun. 80, 410-417 (2012).

22. Gafa, V. et al. Human dendritic cells following Aspergillus fumigatus infection express the CCR7 receptor and a differential pattern of interleukin-12 (IL-12), IL-23, and IL-27 cytokines, which lead to a Th1 response. Infect. Immun. 74, 1480-1489 (2006).

23. Chen, Y. et al. Anti-IL-23 therapy inhibits multiple inflammatory pathways and ameliorates autoimmune encephalomyelitis. J. Clin. Invest. 116, 1317-1326 (2006).

24. Cua, D. J. et al. Interleukin-23 rather than interleukin-12 is the critical cytokine for autoimmune inflammation of the brain. Nature 421, 744-748 (2003).

25. Murphy, C. A. et al. Divergent pro- and antiinflammatory roles for IL-23 and IL-12 in joint autoimmune inflammation. J. Exp. Med. 198, 1951-1957 (2003).

26. Kyttaris, V. C., Zhang, Z., Kuchroo, V. K., Oukka, M. \& Tsokos, G. C. Cutting edge: IL-23 receptor deficiency prevents the development of lupus nephritis in C57BL/6-lpr/lpr mice. J. Immunol. 184, 4605-4609 (2010).

27. Kisielow, P., Bluthmann, H., Staerz, U. D., Steinmetz, M. \& von Boehmer, H. Tolerance in T-cell-receptor transgenic mice involves deletion of nonmature CD4 + 8 + thymocytes. Nature 333, 742-746 (1988).

28. Bluthmann, H. et al. T-cell-specific deletion of T-cell receptor transgenes allows functional rearrangement of endogenous alpha- and beta-genes. Nature 334, 156-159 (1988)

29. von Boehmer, H., Teh, H. S. \& Kisielow, P. The thymus selects the useful, neglects the useless and destroys the harmful. Immunol. Today 10, 57-61 (1989).

30. Farr, A. G., Dooley, J. L. \& Erickson, M. Organization of thymic medullary epithelial heterogeneity: implications for mechanisms of epithelial differentiation. Immunol. Rev. 189, 20-27 (2002).

31. Chen, L., Xiao, S. \& Manley, N. R. Foxn1 is required to maintain the postnatal thymic microenvironment in a dosage-sensitive manner. Blood 113, 567-574 (2009).

32. Bettelli, E. et al. Reciprocal developmental pathways for the generation of pathogenic effector TH17 and regulatory T cells. Nature 441, 235-238 (2006).

33. Veldhoen, M., Hocking, R. J., Atkins, C. J., Locksley, R. M. \& Stockinger, B. TGFbeta in the context of an inflammatory cytokine milieu supports de novo differentiation of IL-17-producing T cells. Immunity 24, 179-189 (2006).

34. Happel, K. I. et al. Cutting edge: roles of Toll-like receptor 4 and IL-23 in IL-17 expression in response to Klebsiella pneumoniae infection. J. Immunol. 170, 4432-4436 (2003).

35. Reay, J., Kim, S. H., Lockhart, E., Kolls, J. \& Robbins, P. D. Adenoviralmediated, intratumor gene transfer of interleukin 23 induces a therapeutic antitumor response. Cancer Gene Ther. 16, 776-785 (2009).

36. Awasthi, A. et al. Cutting edge: IL-23 receptor gfp reporter mice reveal distinct populations of IL-17-producing cells. J. Immunol. 182, 5904-5908 (2009).

37. Sprent, J., Kosaka, H., Gao, E. K., Surh, C. D. \& Webb, S. R. Intrathymic and extrathymic tolerance in bone marrow chimeras. Immunol. Rev. 133, 151-176 (1993).
38. Ron, Y., Lo, D. \& Sprent, J. T cell specificity in twice-irradiated F1-parent bone marrow chimeras: failure to detect a role for immigrant marrow-derived cells in imprinting intrathymic H-2 restriction. J. Immunol. 137, 1764-1771 (1986).

39. Takada, A., Takada, Y., Huang, C. C. \& Ambrus, J. L. Biphasic pattern of thymus regeneration after whole-body irradiation. J. Exp. Med. 129, 445-457 (1969).

40. Ahern, P. P. et al. Interleukin-23 drives intestinal inflammation through direct activity on T cells. Immunity 33, 279-288 (2010)

41. McGeachy, M. J. \& Cua, D. J. The link between IL-23 and Th17 cell-mediated immune pathologies. Semin. Immunol. 19, 372-376 (2007).

42. McGeachy, M. J. et al. The interleukin 23 receptor is essential for the terminal differentiation of interleukin 17-producing effector T helper cells in vivo. Nat. Immunol. 10, 314-324 (2009).

43. Petermann, F. et al. Gammadelta $\mathrm{T}$ cells enhance autoimmunity by restraining regulatory $\mathrm{T}$ cell responses via an interleukin-23-dependent mechanism. Immunity 33, 351-363 (2010).

44. Palmer, E. \& Naeher, D. Affinity threshold for thymic selection through a T-cell receptor-co-receptor zipper. Nat. Rev. Immunol. 9, 207-213 (2009).

45. Gallegos, A. M. \& Bevan, M. J. Central tolerance: good but imperfect. Immunol. Rev. 209, 290-296 (2006).

46. He, Y. W. The role of orphan nuclear receptor in thymocyte differentiation and lymphoid organ development. Immunol. Res. 22, 71-82 (2000).

47. Yarilin, A. A. \& Belyakov, I. M. Cytokines in the thymus: production and biological effects. Curr. Med. Chem. 11, 447-464 (2004).

48. Fernandez, E. et al. Establishment and characterization of cloned human thymic epithelial cell lines. Analysis of adhesion molecule expression and cytokine production. Blood 83, 3245-3254 (1994).

49. Moore, T. A., von Freeden-Jeffry, U., Murray, R. \& Zlotnik, A. Inhibition of gamma delta T cell development and early thymocyte maturation in IL-7 - / mice. J. Immunol. 157, 2366-2373 (1996).

50. Ludviksson, B. R., Ehrhardt, R. O. \& Strober, W. Role of IL-12 in intrathymic negative selection. J. Immunol. 163, 4349-4359 (1999).

51. Galy, A. H. \& Spits, H. IL-1, IL-4, and IFN-gamma differentially regulate cytokine production and cell surface molecule expression in cultured human thymic epithelial cells. J. Immunol. 147, 3823-3830 (1991).

52. Patel, D. D., Whichard, L. P., Radcliff, G., Denning, S. M. \& Haynes, B. F. Characterization of human thymic epithelial cell surface antigens: phenotypic similarity of thymic epithelial cells to epidermal keratinocytes. J. Clin. Immunol. 15, 80-92 (1995)

53. Kuhn, R., Rajewsky, K. \& Muller, W. Generation and analysis of interleukin-4 deficient mice. Science 254, 707-710 (1991).

54. Zlotnik, A., Ransom, J., Frank, G., Fischer, M. \& Howard, M. Interleukin 4 is a growth factor for activated thymocytes: possible role in T-cell ontogeny. Proc. Natl Acad. Sci. USA 84, 3856-3860 (1987).

55. Tepper, R. I. et al. IL-4 induces allergic-like inflammatory disease and alters T cell development in transgenic mice. Cell 62, 457-467 (1990).

56. Park, J. H., Mitnacht, R., Torres-Nagel, N. \& Hunig, T. T cell receptor ligation induces interleukin (IL) $2 \mathrm{R}$ beta chain expression in rat $\mathrm{CD} 4,8$ double positive thymocytes, initiating an IL-2-dependent differentiation pathway of CD8 alpha + /beta- T cells. J. Exp. Med. 177, 541-546 (1993).

57. Savino, W. The thymus is a common target organ in infectious diseases. PLoS Pathog. 2, e62 (2006).

58. Savino, W., Dardenne, M., Velloso, L. A. \& Dayse Silva-Barbosa, S. The thymus is a common target in malnutrition and infection. Br. J. Nutr. 98(Suppl 1): S11-S16 (2007)

59. Sasaki, S., Ishida, Y., Nishio, N., Ito, S. \& Isobe, K. Thymic involution correlates with severe ulcerative colitis induced by oral administration of dextran sulphate sodium in C57BL/6 mice but not in BALB/c mice. Inflammation 31, 319-328 (2008).

60. Dudakov, J. A. et al. Interleukin-22 drives endogenous thymic regeneration in mice. Science 336, 91-95 (2012).

61. Ghoreschi, K. et al. Generation of pathogenic $\mathrm{T}(\mathrm{H}) 17$ cells in the absence of TGF-beta signalling. Nature 467, 967-971 (2010).

62. Langrish, C. L. et al. IL-23 drives a pathogenic T cell population that induces autoimmune inflammation. J. Exp. Med. 201, 233-240 (2005).

63. Eberl, G. et al. An essential function for the nuclear receptor RORgamma(t) in the generation of fetal lymphoid tissue inducer cells. Nat. Immunol. 5, 64-73 (2004).

64. Hsu, H. C. et al. Inhibition of the catalytic function of activation-induced cytidine deaminase promotes apoptosis of germinal center B cells in BXD2 mice. Arthritis Rheum. 63, 2038-2048 (2011).

65. Dreskin, S. C. et al. Measurement of changes in mRNA for IL-5 in noninvasive scrapings of nasal epithelium taken from patients undergoing nasal allergen challenge. J. Immunol. Methods 268, 189-195 (2002). 


\section{Acknowledgements}

We thank Drs. J. Kolls (Louisiana State University) and Paul Robbins (University of Pittsburgh) for providing AdLacZ and AdIL-23; Dr N. Manley (University of Georgia) for technical support in the TEC sorting; and Dr F. Hunter for review of the manuscript. Flow cytometry and confocal imaging data acquisition were carried out at the UAB Comprehensive Flow Cytometry Core (P30 AR048311 and P30 AI027767) and UAB Analytic Imaging and Immunoreagent Core (P30 AR048311), respectively; BioQuant histomorphometry analysis was carried out at the UAB Center for Metabolic Bone Disease-Histomorphometry and Molecular Analysis Core Laboratory (P30 AR46031). This work is supported by grants from VA Merit Review Grant (1I01BX000600-01), NIH/NIAID (1AI 071110, ARRA 3RO1AI71110-02S1 and 1RO1 AI083705),

Rheumatology Research Foundation, Lupus Research Institute, and Arthritis Foundation.

\section{Author contributions}

H.L., H.-C.H. and J.D.M. designed the research and wrote the manuscript. H.L., Q.W., P.Y. J.L., and B.L. conducted the experiments. M.O. provided IL-23R-GFP KI and the homozygous $I l 23 r^{-/-}$mice and discussed the data; D.J.C. provided the $I l 23 p 19^{-/-}$ mice and discussed the data; C.H.S. III contributed to all experiments related with Aspergillus fumigatus infection; W.E.G. contributed to imaging data analysis and interpretation.

\section{Additional information}

Supplementary Information accompanies this paper at http://www.nature.com/ naturecommunications

Competing financial interests: The authors declare no competing financial interests.

Reprints and permission information is available online at http://npg.nature.com/ reprintsandpermissions/

How to cite this article: Li, H. et al. IL-23 promotes TCR-mediated negative selection of thymocytes through the upregulation of IL-23 receptor and ROR $\gamma \mathrm{t}$. Nat. Commun. 5:4259 doi: 10.1038/ncomms5259 (2014). 